\title{
Establishment of Pediatric Reference Intervals for Routine Laboratory Tests in Korean Population: A Retrospective Multicenter Analysis
}

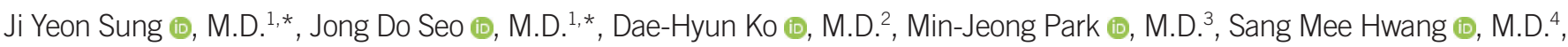

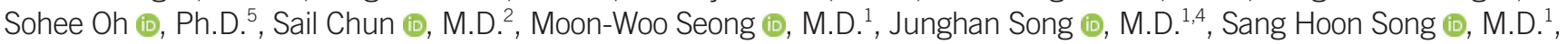
and Sung Sup Park iD, M.D. ${ }^{1}$

${ }^{1}$ Department of Laboratory Medicine, Seoul National University Hospital and College of Medicine, Seoul, Korea; ${ }^{2}$ Department of Laboratory Medicine, University of Ulsan College of Medicine and Asan Medical Center, Seoul, Korea; ${ }^{3}$ Department of Laboratory Medicine, Kangnam Sacred Heart Hospital, Hallym University College of Medicine, Seoul, Korea; ${ }^{4}$ Department of Laboratory Medicine, Seoul National University Bundang Hospital, Seongnam, Korea; ${ }^{5}$ Department of Biostatistics, Seoul Metropolitan Government Seoul National University Boramae Medical Center, Seoul, Korea

Background: Reference intervals defined for adults or children of other ethnicities cannot be applied in the evaluation of Korean pediatric patients. Pediatric reference intervals are difficult to establish because children are in their growing stage and their physiology changes continuously. We aimed to establish reference intervals for routine laboratory tests for Korean pediatric patients through retrospective multicenter data analysis.

Methods: Preoperative laboratory test results from 1,031 pediatric patients aged 0 month-18 years who underwent minor surgeries in four university hospitals were collected. Age- and sex-specific reference intervals for routine laboratory tests were defined based on the Clinical and Laboratory Standards Institute (CLSI) EP28-A3c guidelines.

Results: The pediatric reference intervals determined in this study were different from existing adult reference intervals and pediatric reference intervals for other ethnicities. Most tests required age-specific partitioning, and some of those required sex-specific partitioning for at least one age-partitioned subgroup. Erythrocyte sedimentation rate, monocyte percentage, basophil percentage, activated partial thromboplastin time, glucose, cholesterol, albumin, bilirubin, chloride, and C-reactive protein did not show any difference between age- or sex-partitioned subgroups.

Conclusions: We determined Korean pediatric reference intervals for hematology, coagulation, and chemistry tests by indirect sampling based on medical record data from multiple institutions. These reference intervals would be valuable for clinical evaluations in the Korean pediatric population.

Key Words: Reference intervals, Indirect sampling, Korean pediatrics, Age-partitioned groups, Sex-partitioned groups, Multicenter
Received: January 6, 2020

Revision received: April 8, 2020

Accepted: September 8, 2020

\section{Corresponding author:}

Sang Hoon Song, M.D.

Department of Laboratory Medicine, Seoul National University Hospital and College of Medicine, 101 Daehak-ro, Jongno-gu,

Seoul 03080, Korea

Tel: +82-2-2072-3326

Fax: +82-2-747-0359

E-mail: cloak21@snu.ac.kr

\section{Co-corresponding author:}

Sung Sup Park, M.D.

Department of Laboratory Medicine, Seoul National University Hospital and College of Medicine, 101 Daehak-ro, Jongno-gu,

Seoul 03080, Korea

Tel: +82-2-2072-3206

Fax: +82-2-747-0359

E-mail: sparkle@snu.ac.kr

*These authors equally contributed to this study.

\section{(c) (i) (8)}

(๔) Korean Society for Laboratory Medicine This is an Open Access article distributed under the terms of the Creative Commons Attribution Non-Commercial License (https://creativecommons.org/licenses/by-nc/4.0) which permits unrestricted non-commercial use, distribution, and reproduction in any medium, provided the original work is properly cited.

\section{INTRODUCTION}

Reliable reference intervals for laboratory tests are critical guides for clinicians to diagnose diseases or make medical decisions [1]. The Clinical and Laboratory Standards Institute (CLSI) EP28-A3C guidelines describe procedures for establishing refer- 
ence intervals in a clinical laboratory [2]. Although reference intervals established for a specific population using a specific platform can be transferred to other laboratories after appropriate verification, intervals for adults cannot be reliably adopted for the interpretation of test results of pediatric patients. Pediatric reference intervals should reflect not only age and sex, but also the ongoing growth and development of children [2-5]. Efforts have been made to establish reliable pediatric reference intervals, including studies from the Canadian Laboratory Initiative in Pediatric Reference Intervals (CALIPER) [6-8], German Health Interview and Examination Survey for Children and Adolescents [9, 10], and Children's Health Improvement through Laboratory Diagnostics in the USA [11, 12]. However, some ethnic group studies revealed that ethnicity influences certain test values, such as alanine aminotransferase (ALT) and total protein concentrations [8], and ferritin, total thyroxine, cobalamin, and 25-OH vitamin D in East Asians [13]; thus, reference intervals established for Caucasian populations cannot simply be extrapolated to Asian populations. Another prospective analysis revealed a significant effect of ethnicity on biochemical markers, including $25-\mathrm{OH}$ vitamin $\mathrm{D}$, ferritin, follicle-stimulating hormone, and immunoglobulin M [14]. Therefore, ethnic-specific reference intervals should be determined for certain biochemical markers. There are many previous efforts and some published studies about Korean pediatric reference intervals for biochemical markers including hematology, chemistry, and hormone [15-18]. However, these studies have limitations to assess dynamic age-dependent change in pediatric population. For instance, neither neonates nor infants were included in the reference population $[15,16]$, test samples taken at specific time point from children who underwent 1-year-old check-up, not from whole pediatric period were analyzed [17], or age group between neonate and adult was classified as 'children' without additional subdivision [18]. Korean pediatric reference intervals that cover whole age range have not been established to date.

Establishing pediatric reference intervals is challenging. Especially, collecting a sufficient number of blood samples from healthy children for reference interval establishment and validation are problematic. A small sample size renders the application of simple, nonparametric statistical methods less reliable and requires the use of complicated analytical methods [3, 5, 19, 20]. The CLSI EP28-A3c guidelines suggest conducting a multicenter trial to overcome these problems [2]. Data from multiple centers can be pooled to establish reference intervals when the comparability of the test methods is ensured.

Currently, pediatric reference intervals are rarely provided when laboratory test results are reported in Korea, and when provided, they are usually based on studies in other ethnic populations. Moreover, existing reference intervals were established using old measurement methods, and instruments and are not applicable to current methods or instruments used in laboratories. Therefore, we aimed to establish reliable age- and sex-specific Korean pediatric reference intervals for hematology, coagulation, and chemistry tests.

\section{MATERIALS AND METHODS}

\section{Data collection}

Four university hospitals, i.e., Seoul National University Hospital (SNUH, Seoul), Seoul National University Bundang Hospital (SNUBH, Seongnam), Asan Medical Center (AMC, Seoul), and Kangnam Sacred Heart Hospital (KSHH, Seoul), Korea, participated in this retrospective study. Patients aged 0 month-18 years who visited any of the hospitals between June 2010 and August 2015 were selected for potential inclusion in this study. No analytical drift was noted in any of the hospitals during the period of data collection, including alteration in instrument or reagent, and a notable internal quality control issue.

In accordance with CLSI EP28-A3c guidelines, to obtain data from "presumed healthy" individuals [2, 21], patients who underwent routine preoperative laboratory evaluation for minor surgery in the departments of general surgery, orthopedics, plastic surgery, thoracic surgery, ophthalmology, otorhinolaryngology, urology, dermatology, and dental surgery were considered as the "healthy" pediatric population. Preoperative laboratory test results of these patients were collected as reference values, following the indirect sampling method [2]. Basic demographic and laboratory data were extracted from the medical records to exclude patients with "unhealthy" general conditions or any underlying diseases. Patients with the following conditions were considered "unhealthy" and were therefore excluded: those taking prescribed medicines, those with any other comorbidity, those with febrile disease within two weeks before blood sampling for laboratory tests, those whose planned surgery was canceled after assessment of the laboratory test results, and those with other diseases requiring treatment at the time of blood sampling. As bone-specific alkaline phosphatase is elevated when bone injuries occur [22, 23], ALP values from orthopedic patients were considered inappropriate for the present study and were excluded.

The patients included in the final analysis largely had mild diseases unlikely to affect the laboratory test results. Only results 
from samples that passed the acceptance criteria of each hospital for each test, including volume, and were verified without warning or additional comment about hemolytic, icteric, or lipemic interferences, were included.

Referring to previous studies $[8,24]$ and considering the size of the reference group, the patients were divided into six subgroups by age: 0-3 months, 4-11 months, 1-6 years, 7-12 years, 13-15 years, and 16-18 years, and two subgroups by sex, to establish age- and sex-partitioned pediatric reference intervals. Finally, we extracted data for a total of 1,031 Korean pediatric patients from the four hospitals, including 401, 302, 228, and 100 patients from SNUH, AMC, SNUBH, and KSHH, respectively. The size of the aforementioned age-partitioned six subgroups was 44 (22 boys, 22 girls), 258 (140 boys, 118 girls), 415 (231 boys, 184 girls), 141 (76 boys, 65 girls), 101 (49 boys, 52 girls), and 72 (31 boys, 41 girls), respectively (Supplemental Data Table S1).

The study protocol was approved by the Institutional Review Board of each participating hospital. Informed consent was waived as this was a minimal risk study using only the test results stored in a database.

\section{Laboratory tests and analytical methods}

Preoperative routine laboratory test results were used for the reference interval analysis. The laboratory tests included hematology: white blood cell count with absolute neutrophil count, percentage of neutrophils, lymphocytes, monocytes, eosinophils, and basophils; red blood cell (RBC) count with mean corpuscular volume (MCV), mean corpuscular hemoglobin ( $\mathrm{MCH}$ ), and mean corpuscular hemoglobin concentration $(\mathrm{MCHC})$, hemoglobin $(\mathrm{Hb})$, hematocrit (Hct), RBC distribution width (RDW) and erythrocyte sedimentation rate (ESR); platelet count with mean platelet volume (MPV), plateletcrit (PCT) and platelet distribution width (PDW); coagulation: prothrombin time (PT), activated partial thromboplastin time (aPTT), and fibrinogen; chemistry: calcium (Ca), phosphorus (P), blood urea nitrogen (BUN), creatinine $(\mathrm{Cr})$, protein, albumin, uric acid, aspartate aminotransferase (AST), ALT, ALP, bilirubin, glucose, cholesterol, sodium ( $\mathrm{Na}$ ), potassium (K), chloride (Cl), total $\mathrm{CO} 2$ (TCO2), and C-reactive protein (CRP).

For hematology tests, Sysmex XE-2100 (Sysmex Corporation, Kobe, Japan) was used in SNUH, SNUBH, and AMC, and Advia2120 (Siemens, Washington, DC, USA) in KSHH. For coagulation tests, ACL TOP (Instrumentation Laboratory, Bedford, MA, USA) was used in SNUH and KSHH, Sysmex CA-7000 (Sysmex Corporation, Kobe, Japan) in AMC, and STA-R MAX (Diagnos- tica Stago Inc., Asnières, France) in SNUBH. For chemistry tests, TBA-c16000 (Toshiba, Tokyo, Japan) was used in SNUH, AU 5800 (Beckman Coulter, Brea, CA, USA) in SNUBH, COBAS 8000 (Roche Diagnostic International Ltd., Rotkreuz ZG, Switzerland) in AMC, and Hitachi 7600 (Hitachi, Tokyo, Japan) in $\mathrm{KSHH}$.

\section{Comparison of test methods}

We conducted a test method comparison and bias estimation to ensure comparability of the data from the different hospitals using diverse platforms and analytical methods, and to evaluate the possibility of establishing common reference intervals applicable to multiple analytical platforms. Fifty-one pooled serum samples were prepared in SNUH using residual serum stored at $4^{\circ} \mathrm{C}$ for three days, with $2-\mathrm{mL}$ aliquots from each sample set distributed to the participating hospitals, and subsequently evaluated at the day of receipt for chemistry tests for $\mathrm{Ca}, \mathrm{P}, \mathrm{BUN}$, $\mathrm{Cr}$, protein, albumin, uric acid, AST, ALT, ALP, total bilirubin, glucose, cholesterol, $\mathrm{Na}, \mathrm{K}, \mathrm{Cl}$, and TCO2. We compared only chemistry tests because of the difficulty in controlling the many factors that are to be considered when preparing pooled samples to compare hematology and coagulation test methods, such as blood type and isoagglutinin, unexpected antibody, and the condition of the plasma in which the cells were incubated. The hematology and coagulation tests from diverse platforms were indirectly compared by reviewing external quality assessment result, and analyzing the results using Mann-Whitney $U$ test; however, this did not provide evidence enough to justify data combining. Equivalence of the chemistry test results was evaluated by Deming regression: when the $95 \%$ confidence interval $(\mathrm{Cl})$ of the slope contained 1 and that of the intercept contained $\mathrm{O}$, and reference material for each analyte was available in the Joint Committee for Traceability in Laboratory Medicine (JCTLM) database [25], the data from each hospital were regarded valid for reference interval determination and were merged for analysis. Chemistry tests results obtained from a single instrument, TBA-c16000, and from multiple equivalent platforms were analyzed to determine platform-specific and common reference intervals, respectively, whereas results obtained at SNUH using Sysmex XE-2100 and ACL TOP were used to determine platform-specific reference intervals for hematology and coagulation tests.

\section{Data analysis and reference interval determination}

The data were analyzed as recommended by the CLSI EP28A3c guidelines [2]. The approach to establish reference inter- 
vals was similar to that used in the CALIPER study [8]. First, distribution tables and scatter plots were generated to globally assess the data. When the raw data were not normally distributed, they were subjected to logarithmic or Box-Cox transformation, and then, outliers for each test, confirmed by applying the Tukey test twice, were removed [26]. Partitioning of the reference interval according to age and sex was evaluated by Harris and Boyd's test, using the mean, standard deviation (SD), and sample size of the subgroups [1]. If no significant difference was found between the partitioned reference intervals of adjacent age or sex subgroups, these subgroups were merged and the reference intervals for the merged group were re-assessed against those for the adjacent subgroup using the Harris and Boyd's test, until no mergeable subgroups remained. When the sample size of the subgroup was $\geq 120$, we defined the 2.5th and 97.5th percentiles as the lower and upper reference limits, respectively, according to the nonparametric method, and the
$90 \% \mathrm{Cl}$ of the limit was determined. When the sample size was $<120$, the robust method reported by Horn, et al. [27] was used to set the reference intervals and calculate the $90 \% \mathrm{Cl}$, except for a few tests, in which this method is inadequate to calculate the reference lower limit. The parametric method, which defines the range of mean $\pm 2 S D$ as reference interval, was applied for these tests after Shapiro-Wilk normality test. Statistical analyses were performed using Excel 2013 (Microsoft, Redmond, WA, USA), IBM SPSS Statistics 23 (IBM, Armonk, NY, USA), EP Evaluator 11 (Data Innovations, Burlington, VT, USA), and MedCalc version 14.8.1 (MedCalc Software, Ostend, Belgium).

\section{RESULTS}

\section{Hematology}

Details of the reference intervals for hematology testing using

Table 1. Age- and sex-specific pediatric reference intervals for hematology testing using the Sysmex XE-2100 system

\begin{tabular}{|c|c|c|c|c|c|c|}
\hline Analyte (unit) & Total N & Age & Sex & $\mathrm{N}$ & Lower limit $(90 \% \mathrm{Cl})$ & Upper limit (90\% Cl) \\
\hline \multirow[t]{5}{*}{ WBC $\left(\times 10^{9} / L\right)$} & 385 & 0-3 mo & M & 17 & $6.48(4.74-8.10)$ & 16.30 (14.52-17.68) \\
\hline & & & $\mathrm{F}$ & 17 & $5.78(4.12-7.66)$ & $15.80(14.05-17.00)$ \\
\hline & & 4-11 mo & Both & 67 & $4.64(3.78-5.42)$ & 13.85 (12.98-14.77) \\
\hline & & $1-6 \mathrm{yr}$ & Both & 138 & $4.85(4,62-5,60)$ & 11.50 (11.09-11.90) \\
\hline & & $7-18 \mathrm{yr}$ & Both & 146 & $4,32(2,72-4,62)$ & $10.22(9.57-10.20)$ \\
\hline \multirow[t]{2}{*}{$\operatorname{ANC}\left(\times 10^{9} / \mathrm{L}\right)$} & 383 & 0-11 mo & Both & 97 & $0.65 *(N / A)$ & $3.35 *(N / A)$ \\
\hline & & $1-18 \mathrm{yr}$ & Both & 286 & $1.40(1.22-1.51)$ & $5.76(5.42-5.96)$ \\
\hline \multirow[t]{4}{*}{ Segmented neutrophils (\%) } & 393 & 0-11 mo & Both & 101 & $3.3(1.1-5.5)$ & $33.1(30.1-35.6)$ \\
\hline & & $1-6 \mathrm{yr}$ & Both & 147 & $16.9(12.8-19.0)$ & $62.2(56.3-65.6)$ \\
\hline & & $7-12 \mathrm{yr}$ & Both & 46 & $28.4(25.1-32.2)$ & $64.5(60.5-68.3)$ \\
\hline & & $13-18 \mathrm{yr}$ & Both & 99 & $38.3(36.4-40.3)$ & $67.7(65.6-69.8)$ \\
\hline \multirow[t]{4}{*}{ Lymphocytes (\%) } & 391 & 0-11 mo & Both & 100 & $54.5(52.0-57.6)$ & $87.6(85.2-89.8)$ \\
\hline & & $1-6 \mathrm{yr}$ & Both & 147 & $26.9(24.9-35.1)$ & $73.8(72.6-77.5)$ \\
\hline & & $7-12 \mathrm{yr}$ & Both & 45 & $29.4(26.2-32.8)$ & $59.3(56.3-62.0)$ \\
\hline & & $13-18 \mathrm{yr}$ & Both & 99 & $21.5(19.3-23.6)$ & $51.5(49.5-53.6)$ \\
\hline Monocytes (\%) & 387 & All & Both & 387 & $3.5(3.0-3.7)$ & $10.4(10.0-10.7)$ \\
\hline \multirow[t]{2}{*}{ Eosinophils (\%) } & 375 & All & M & 181 & $0.3(0.1-0.7)$ & $6.9(6.4-7.3)$ \\
\hline & & & $\mathrm{F}$ & 194 & $0.4(0.1-0.7)$ & $5.7(4.9-5.9)$ \\
\hline Basophils (\%) & 380 & All & Both & 380 & $0.1(0.1-0.1)$ & $0.8(0.8-0.9)$ \\
\hline \multirow[t]{3}{*}{$\mathrm{RBC}\left(\times 10^{6} / \mu \mathrm{L}\right)$} & 390 & $0-3$ mo & Both & 32 & $3.22(3.07-3.41)$ & $4.65(4.44-4.82)$ \\
\hline & & $4 \mathrm{mo}-18 \mathrm{yr}$ & M & 174 & $4.16(4.09-4.29)$ & $5.49(5.30-5.62)$ \\
\hline & & & $F$ & 184 & $4.03(3.86-4.10)$ & $5.16(5.03-5.29)$ \\
\hline \multirow[t]{5}{*}{ MCV (fL) } & 395 & $0-3 \mathrm{mo}$ & Both & 35 & $73.9(71.2-76.6)$ & $98.3(95.2-100.9)$ \\
\hline & & 4-11 mo & M & 34 & $68.6(66.9-70.6)$ & $82.8(81.0-84.5)$ \\
\hline & & & $\mathrm{F}$ & 35 & 70.8 (69.1-72.5) & $84.6(82.8-86.2)$ \\
\hline & & $1-6 \mathrm{yr}$ & M & 73 & $72.3(71.5-73.2)$ & $83.4(82.5-84.3)$ \\
\hline & & & $\mathrm{F}$ & 72 & $73.9(72.8-75.0)$ & $86.1(85.2-87.0)$ \\
\hline
\end{tabular}


Table 1. Continued

\begin{tabular}{|c|c|c|c|c|c|c|}
\hline Analyte (unit) & Total N & Age & Sex & $\mathrm{N}$ & Lower limit (90\% Cl) & Upper limit (90\% Cl) \\
\hline & & $7-12 \mathrm{yr}$ & M & 22 & $74.7(73.1-76.6)$ & 87.8 (85.7-89.8) \\
\hline & & & $\mathrm{F}$ & 26 & $78.3(77.0-79.9)$ & $89.0(87.6-90.3)$ \\
\hline & & $13-15 \mathrm{yr}$ & M & 27 & $76.4(74.3-78.7)$ & $93.3(91.1-95.3)$ \\
\hline & & & $\mathrm{F}$ & 35 & $80.5(79.0-82.1)$ & $94.3(92.6-96.0)$ \\
\hline & & $16-18 \mathrm{yr}$ & M & 18 & $80.3(78.3-82.6)$ & $95.2(92.4-97.8)$ \\
\hline & & & $\mathrm{F}$ & 18 & $83.4(81.6-85.6)$ & $95.9(93.9-97.5)$ \\
\hline \multirow[t]{7}{*}{ MCH (pg) } & 390 & $0-3 \mathrm{mo}$ & Both & 35 & $25.3(24.4-26.4)$ & 33.7 (32.7-34.6) \\
\hline & & 4-11 mo & M & 32 & $23.5(22.8-24.2)$ & $28.6(28.0-29.2)$ \\
\hline & & & $\mathrm{F}$ & 31 & $24.9(24.5-25.4)$ & $28.2(27.9-28.5)$ \\
\hline & & $1-6 \mathrm{yr}$ & Both & 146 & $24.6(24.3-25.2)$ & $29.1(28.8-29.3)$ \\
\hline & & $7-12 \mathrm{yr}$ & Both & 48 & $26.4(26.0-26.7)$ & $30.4(29.9-30.8)$ \\
\hline & & $13-15$ yr & Both & 62 & $26.4(25.8-26.9)$ & $32.2(31.7-32.7)$ \\
\hline & & $16-18 \mathrm{yr}$ & Both & 36 & $28.0(27.5-28.6)$ & $32.3(31.8-32.8)$ \\
\hline \multirow[t]{3}{*}{ MCHC (g/L) } & 386 & $0-12 \mathrm{yr}$ & Both & 298 & 327 (325-329) & 359 (357-364) \\
\hline & & $13-18 \mathrm{yr}$ & M & 44 & 325 (322-328) & $357(354-360)$ \\
\hline & & & $\mathrm{F}$ & 44 & $323(321-326)$ & $343(341-345)$ \\
\hline \multirow[t]{8}{*}{$\mathrm{Hb}(\mathrm{g} / \mathrm{L})$} & 393 & $0-3 \mathrm{mo}$ & Both & 33 & $97(92-101)$ & $134(128-140)$ \\
\hline & & $4 \mathrm{mo}-6 \mathrm{yr}$ & Both & 214 & $108(107-111)$ & $140(138-143)$ \\
\hline & & $7-12 \mathrm{yr}$ & M & 23 & $117^{\dagger}(112-123)$ & $154^{\dagger}(148-159)$ \\
\hline & & & $\mathrm{F}$ & 25 & $115(110-120)$ & 148 (143-152) \\
\hline & & $13-15$ yr & M & 27 & 124 (119-129) & 164 (158-169) \\
\hline & & & $\mathrm{F}$ & 34 & 118 (114-122) & $150(146-152)$ \\
\hline & & $16-18 \mathrm{yr}$ & M & 18 & $138^{\dagger}(132-143)$ & $170^{\dagger}(164-176)$ \\
\hline & & & $\mathrm{F}$ & 19 & $119^{\dagger}(114-123)$ & $146^{\dagger}(141-151)$ \\
\hline \multirow[t]{7}{*}{ Hct (proportion of 1.0) } & 380 & $0-3 \mathrm{mo}$ & Both & 27 & $0.31(0.30-0.31)$ & $0.36(0.36-0.37)$ \\
\hline & & 4 mo-6 yr & Both & 211 & $0.33(0.32-0.33)$ & $0.40(0.39-0.41)$ \\
\hline & & $7-12$ yr & Both & 48 & $0.34(0.34-0.35)$ & $0.43(0.42-0.44)$ \\
\hline & & $13-15 \mathrm{yr}$ & M & 27 & $0.36(0.34-0.37)$ & $0.48(0.46-0.50)$ \\
\hline & & & $\mathrm{F}$ & 34 & $0.36(0.35-0.37)$ & $0.44(0.43-0.45)$ \\
\hline & & $16-18 \mathrm{yr}$ & M & 18 & $0.40(0.39-0.42)$ & $0.50(0.49-0.52)$ \\
\hline & & & $\mathrm{F}$ & 15 & $0.36^{\dagger}(0.35-0.37)$ & $0.42^{\dagger}(0.41-0.43)$ \\
\hline \multirow[t]{4}{*}{ RDW (\%) } & 390 & $0-3 \mathrm{mo}$ & Both & 35 & $11.7(11.2-12.2)$ & $16.3(15.7-16.8)$ \\
\hline & & 4 mo-6 yr & M & 105 & $12.0(11.8-12.1)$ & $14.4(14.2-14.6)$ \\
\hline & & & $\mathrm{F}$ & 106 & $11.7(11.5-11.9)$ & $14.1(13.9-14.3)$ \\
\hline & & $7-18 \mathrm{yr}$ & Both & 144 & $11.7(11.3-11.9)$ & $13.8(13.6-13.8)$ \\
\hline ESR $(\mathrm{mm} / \mathrm{hr})$ & 225 & All & Both & 225 & $2(2-2)$ & $9(8-9)$ \\
\hline \multirow[t]{4}{*}{ Platelets $\left(\times 10^{9} / \mathrm{L}\right)$} & 390 & $0-3 \mathrm{mo}$ & Both & 35 & 188 (143-243) & $610(558-663)$ \\
\hline & & 4-11 mo & Both & 65 & 199 (174-224) & $495(467-520)$ \\
\hline & & $1-12 \mathrm{yr}$ & Both & 192 & 178 (171-192) & 414 (389-434) \\
\hline & & $13-18 \mathrm{yr}$ & Both & 98 & 165 (151-179) & 365 (351-379) \\
\hline \multirow[t]{2}{*}{ РСТ (\%) } & 390 & 0-11 mo & Both & 102 & $0.17(0.15-0.19)$ & $0.52(0.49-0.54)$ \\
\hline & & $1-18 \mathrm{yr}$ & Both & 288 & $0.17(0.15-0.18)$ & $0.38(0.36-0.39)$ \\
\hline \multirow[t]{2}{*}{ MPV (fL) } & 373 & $0-6$ yr & Both & 236 & $7.6(7.5-8.0)$ & $10.9(10.5-11.1)$ \\
\hline & & $7-18 \mathrm{yr}$ & Both & 137 & $8.8(8.6-9.1)$ & $11.4(11.1-11.8)$ \\
\hline PDW (\%) & 358 & All & Both & 358 & $8.4(8.1-8.6)$ & $13.3(12.9-13.7)$ \\
\hline
\end{tabular}

*Although the sample size was $<120$, the values presented were established using a nonparametric method because the $90 \% \mathrm{Cl}$ of the reference lower limit calculated using the robust method contained a negative value and the data did not pass a normality test; ${ }^{\dagger}$ The $90 \% \mathrm{Cl}$ was not determined using the robust method; however, the data passed a normality test and a parametric method based on the normal distribution was applied.

Abbreviations: $\mathrm{Cl}$, confidence interval; N/A, not applicable; yr, year; mo, month; M, male; F, female; ANC, absolute neutrophil count; MCH, mean corpuscular hemoglobin; MCHC, mean corpuscular hemoglobin concentration; RDW, red cell distribution width; PCT, plateletcrit; MPV, mean platelet volume; PDW, platelet distribution width; WBC, white blood cells; RBC, red blood cells; MCV, mean corpuscular volume; ESR, erythrocyte sedimentation rate; Hct, hematocrit. 
the Sysmex XE-2100 are shown in Table 1. Most hematology tests showed significantly different results between two or more adjacent age-partitioned subgroups. Especially, values for children younger than 3 months or 1 year tended to differ from those of older children. Sex-partitioned reference intervals were established for some tests in at least one age-partitioned subgroup. A few tests, including ESR, monocyte percentage, basophil percentage, and PDW, did not show any significant difference between age- or sex-partitioned subgroups; thus, all results for these tests were combined to establish common pediatric reference intervals.

\section{Coagulation}

Reference intervals for coagulation tests established on the basis of test results obtained at SNUH using ACL TOP are shown Table 2. In the coagulation tests, we observed age-specific differences between children younger and older than one year for PT and younger and older than 13 years for fibrinogen concentration, whereas aPTT did not show age-specific differences. None of the coagulation tests showed sex-specific differences.

\section{Chemistry}

Reference intervals for chemistry tests established using TBAc16000 as well as from the various platforms are shown in Table 3. This table also presents pediatric reference intervals established in previous studies, including a single-center study in a Korean population established using Hitachi 7600 [15] and the CALIPER study using Abbott Architect c8000 [8]. Test items for which the multicenter results were equivalent to those obtained using the TBA-c16000 instrument in the method comparison test were combined to establish multicenter reference intervals.
For some test items, the comparison based on Deming regression revealed adequate equivalence (Supplemental Data Table S2) to results obtained from at least one of the other platforms, AU 5800, Cobas 8000, Hitachi 7600, and reference material was available in the JCTLM database (Supplemental Data Table S3); therefore, data obtained for these items were mergeable with those obtained using the TBA-c16000 instrument. Results of Ca testing on Cobas 8000 and Hitachi 7600, glucose testing on Cobas 8000, cholesterol testing on Hitachi 7600, Na testing on all instruments, and $\mathrm{K}$ and $\mathrm{Cl}$ testing on Cobas 8000 and $\mathrm{AU}$ 5800 were used to establish reference intervals (Table 3). For most chemistry tests, age-partitioned reference intervals were established. Glucose, cholesterol, albumin, bilirubin, $\mathrm{Cl}$, and CRP did not show any difference between age-partitioned subgroups. For $\mathrm{P}$, uric acid, protein, ALP, AST, and $\mathrm{Cr}$, sex-specific reference intervals were established for at least one age-partitioned subgroup.

Hematology, coagulation, and chemistry tests that showed age-dependent changes are presented as scatter plots in Figs. 1,2 , and 3 , respectively. In hematology, segmented neutrophil percentage, hemoglobin, and hematocrit tended to increase with age (Fig. 1B, 1I, and $1 \mathrm{~J}$ ), whereas WBC count, lymphocyte percentage, and platelets tended to decrease with age (Fig. $1 \mathrm{~A}$, $1 \mathrm{C}$, and $1 \mathrm{~L}$ ). For chemistry, pediatric reference intervals established previously based mainly on a Caucasian population [8] are indicated as horizontal dashed lines in Fig. 3. Minor differences in reference intervals between ethnicities are indicated in Table 3; however, these differences were too small to be visible in Fig. 3. In Fig. 3, all mergeable multicenter data are plotted. BUN, uric acid, and $\mathrm{Cr}$ tended to increase with age (Fig. 3C, 3I, and $3 \mathrm{D}$ ), whereas $\mathrm{P}$, and $\mathrm{K}$ tended to decrease with age (Fig.

Table 2. Age-specific pediatric reference intervals for coagulation testing using the ACL TOP system

\begin{tabular}{lcccccc}
\hline Analyte (unit) & Total N & Age & Sex & N & Lower limit (90\% Cl) & Upper limit (90\% Cl) \\
\hline PT INR & 389 & $0-11 \mathrm{mo}$ & Both & 102 & $0.87(0.85-0.89)$ & $1.14(1.12-1.16)$ \\
& & $1-18 \mathrm{yr}$ & Both & 287 & $0.93(0.91-0.94)$ & $1.17(1.15-1.19)$ \\
PT (\%) & 392 & $0-11 \mathrm{mo}$ & Both & 100 & $82(79-84)$ & $117(114-120)$ \\
& & $1-18 \mathrm{yr}$ & Both & 292 & $78(73-81)$ & $111(109-114)$ \\
PT (s) & 387 & $0-11 \mathrm{mo}$ & Both & 100 & $9.6(9.4-9.8)$ & $12.3(12.1-12.5)$ \\
& & $1-18 \mathrm{yr}$ & Both & 287 & $10.1(10.0-10.3)$ & $12.8(12.6-13.1)$ \\
aPTT (s) & 383 & All & Both & 383 & $28.3(27.5-29.0)$ & $41.3(40.8-41.7)$ \\
Fibrinogen (g/dL) & 67 & $0-12 \mathrm{yr}$ & Both & 56 & $1.46(1.31-1.63)$ & $3.21(3.04-3.35)$ \\
& & $13-18 \mathrm{yr}$ & Both & 11 & $1.96^{*}(1.54-2.37)$ & $3.79 *(3.38-4.21)$ \\
\hline
\end{tabular}

${ }^{*}$ The $90 \% \mathrm{Cl}$ was not determined using a non-parametric method or robust method; however, the data passed a normality test and a parametric method based on the normal distribution was applied.

Abbreviations: PT, prothrombin time; INR, international normalized ratio; aPTT, activated partial thromboplastin time; yr, year; mo, month. 


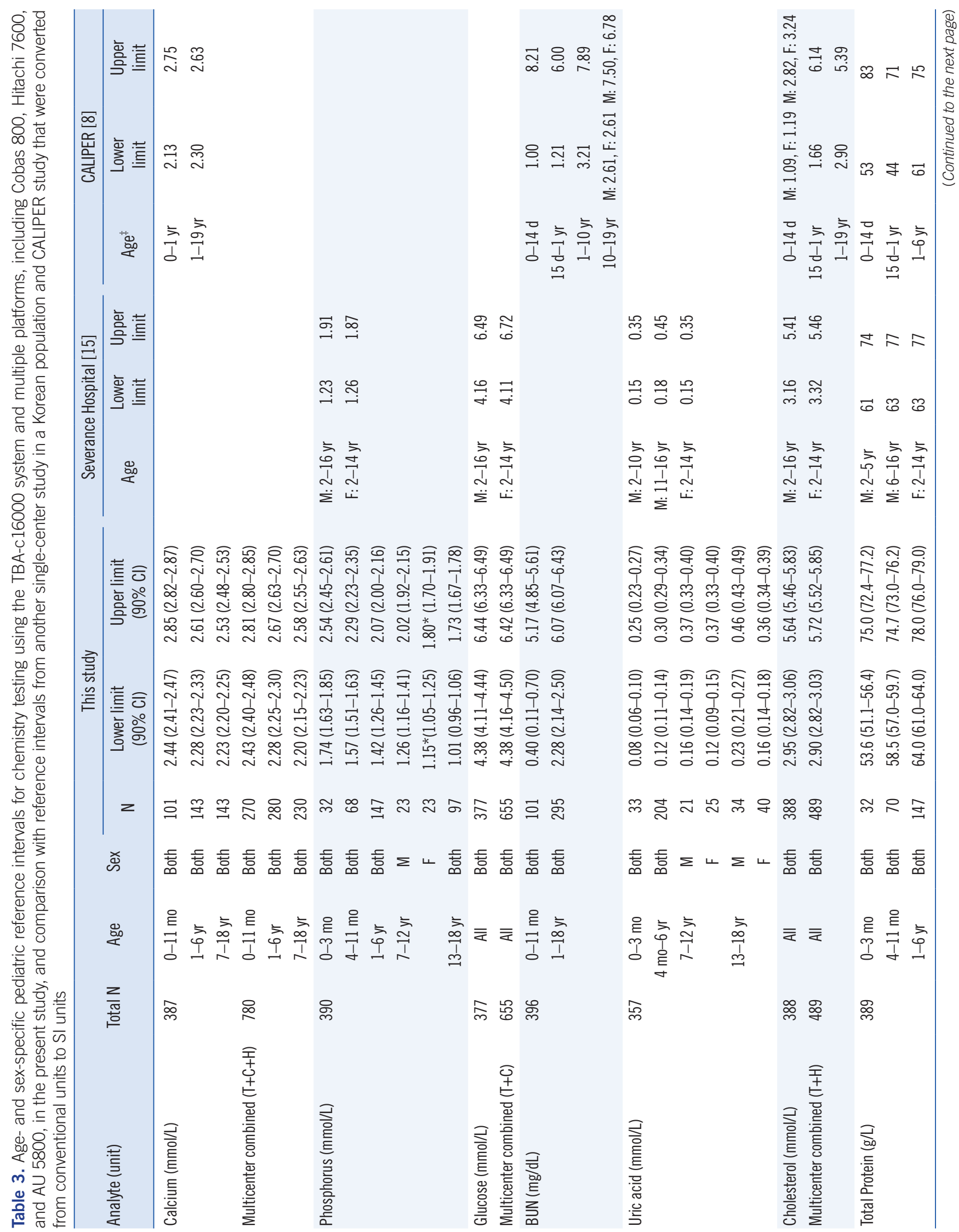




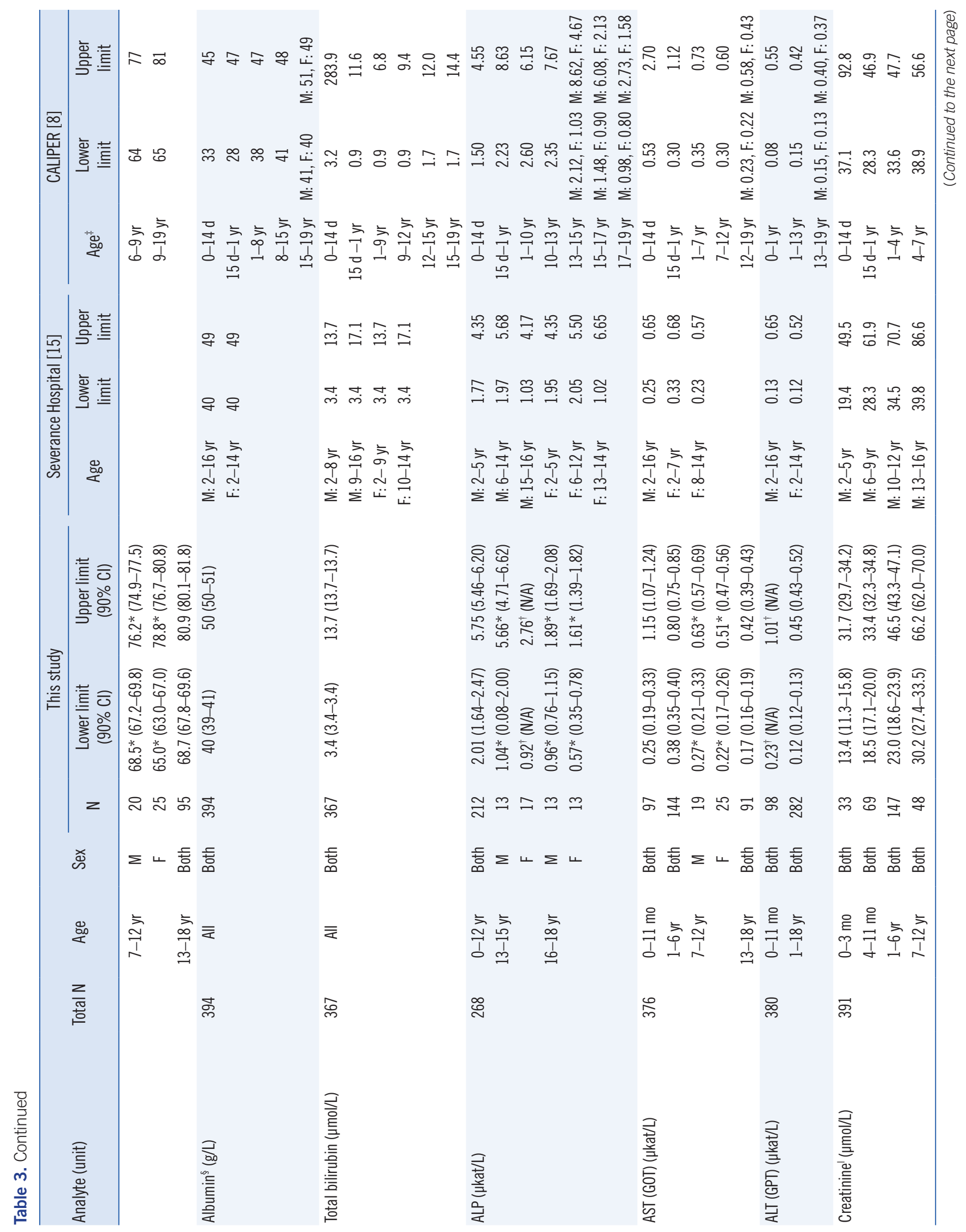




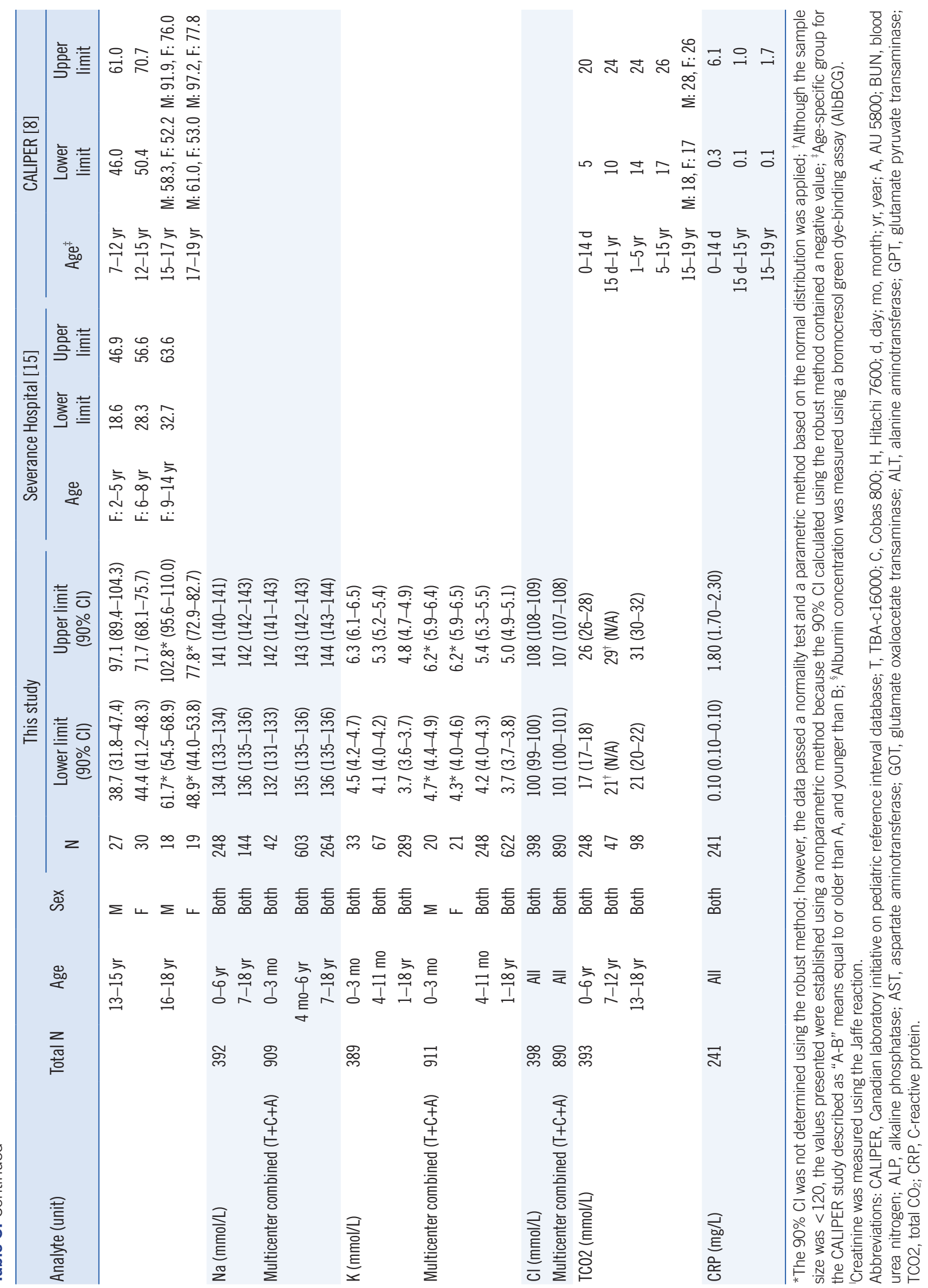


A

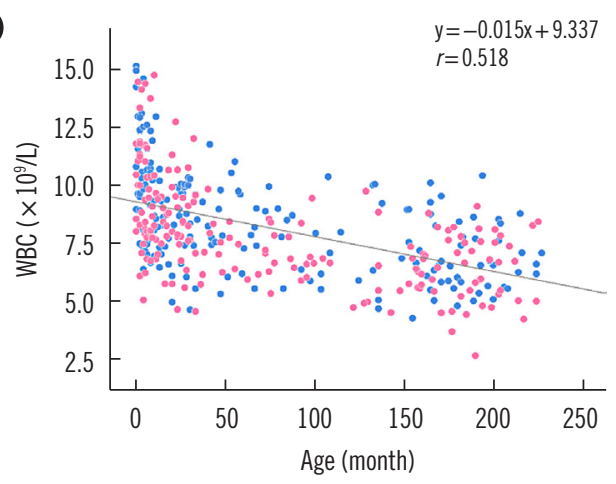

C

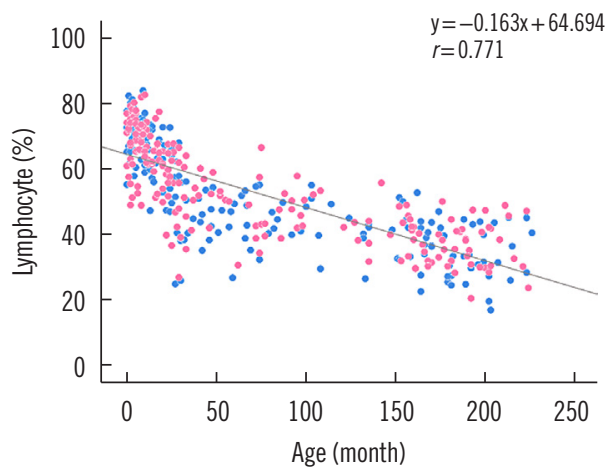

E

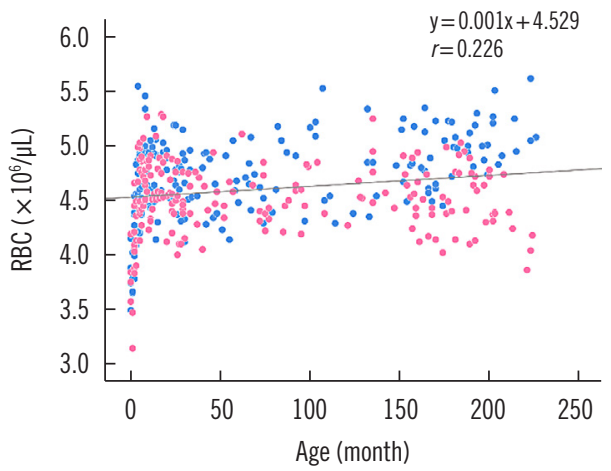

G

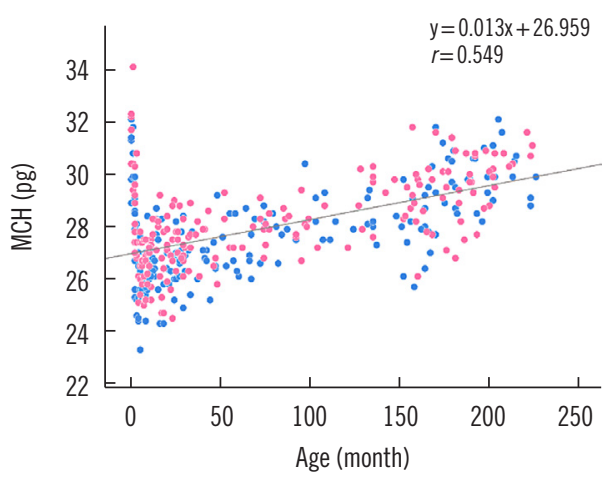

B

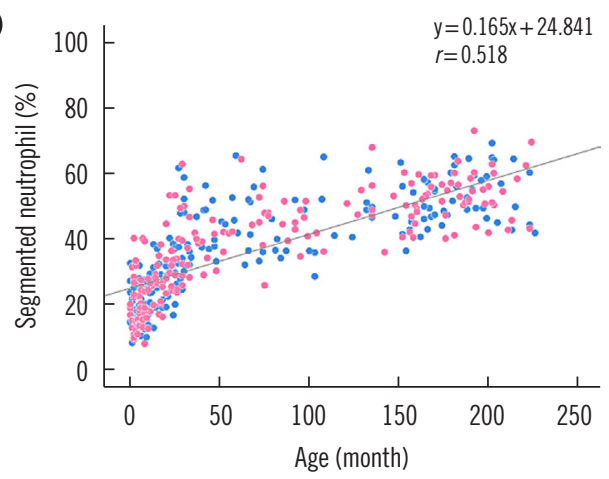

(D)

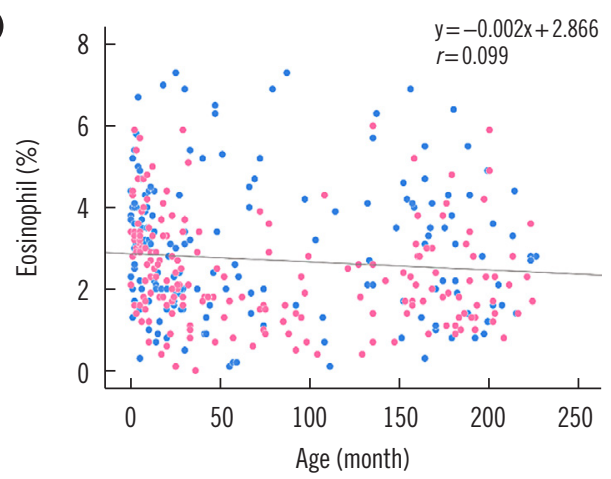

F

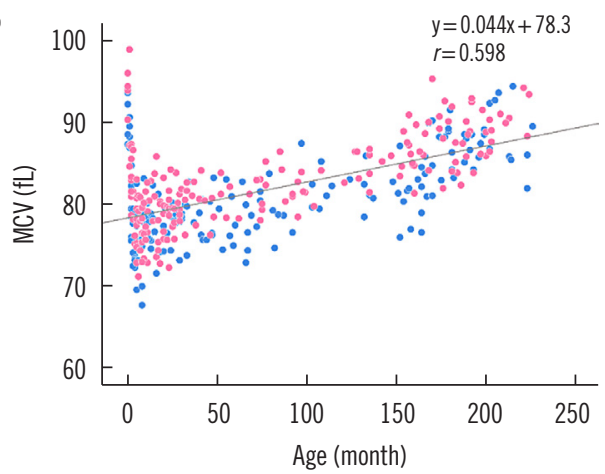

H

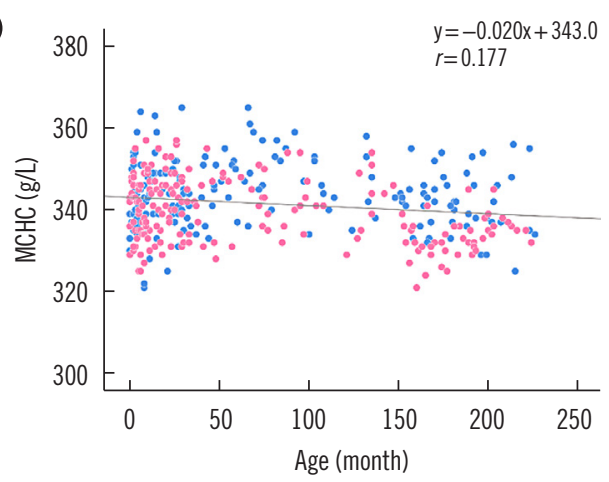

Fig. 1. Scatter plots of hematology test results showing age-dependent changes. Results obtained at SNUH using the Sysmex XE-2100 platform after outlier exclusion are presented. (A-D) WBC count, percentage of segmented neutrophils, lymphocytes, and eosinophils. (E-K) $\mathrm{RBC}$ count, $\mathrm{MCV}, \mathrm{MCH}, \mathrm{MCHC}$, hemoglobin concentration, hematocrit, and RDW.

(Continued to the next page) 
(1)

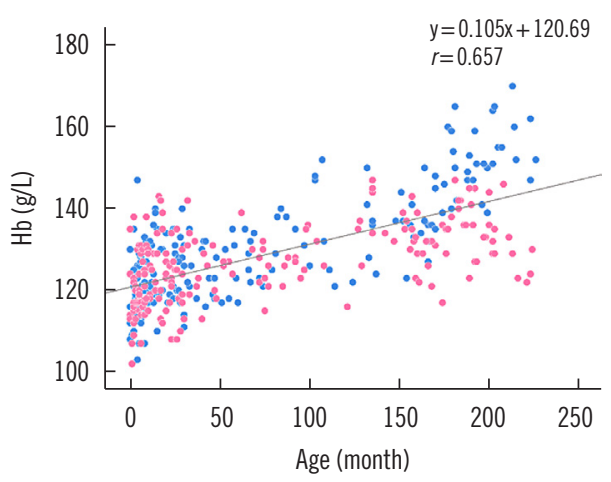

《

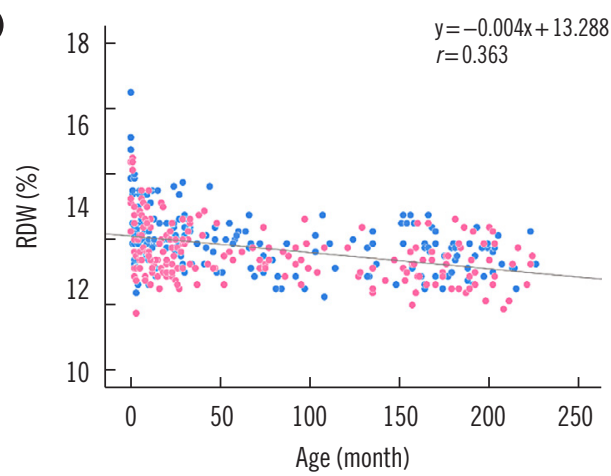

(11)

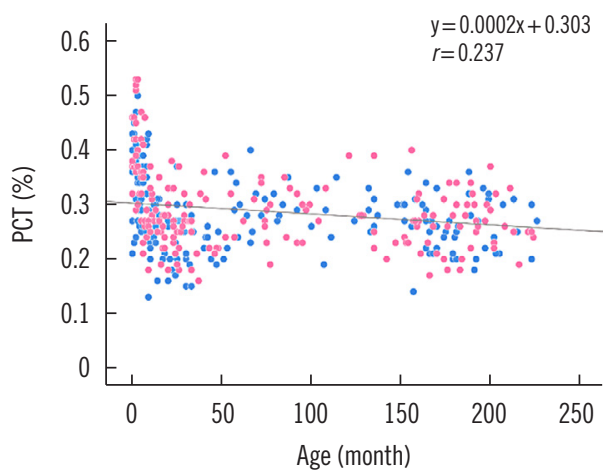

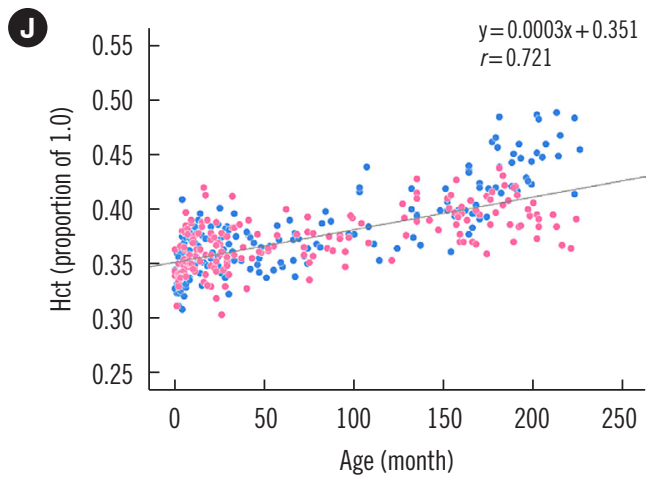

()

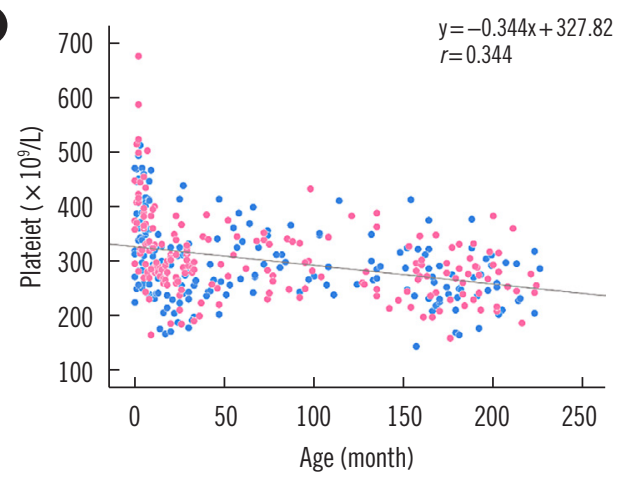

(

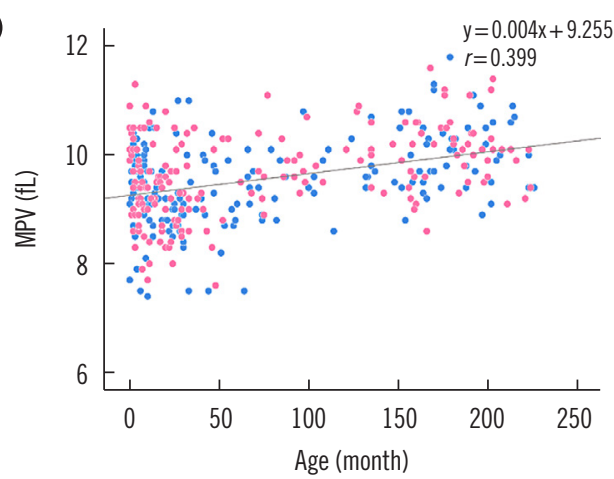

Fig. 1. Continued. ( $L-N)$ platelet count, PCT, and MPV. Blue and red dots represent male and female children enrolled in the present study. The gray line represents the trend line; its equation and $r$ value are given.

Abbreviations: SNUH, Seoul National University Hospital; WBC, white blood cell; MCV, mean corpuscular volume; MCH, mean corpuscular hemoglobin; $\mathrm{MCHC}$, mean corpuscular hemoglobin concentration; RBC, red blood cell; RDW, RBC distribution width; PCT, plateletcrit; MPV, mean platelet volume; Hct, hematocrit.

3B and $3 \mathrm{~K})$. Reference intervals for tests that showed age-dependent changes largely differed from adult reference intervals. Tests that did not show age-dependent changes and for which no age-specific reference intervals were established are presented as scatter plots in Supplemental Data Figs. S1 and S2.

\section{DISCUSSION}

Although indirect sampling for establishing reference intervals is controversial $[28,29]$, and the CLSI working group does not endorse this method as a primary approach [2], some studies support well-designed indirect sampling methods [30-33]. While the possibility of including "unhealthy" patients in the reference group cannot be completely excluded owing to the intrinsic limitation of this approach, best efforts to derive reliable, sophisticated results from data have been made by careful medical record review and discussion by the international CALIPER research team, which leads studies on the establishment 

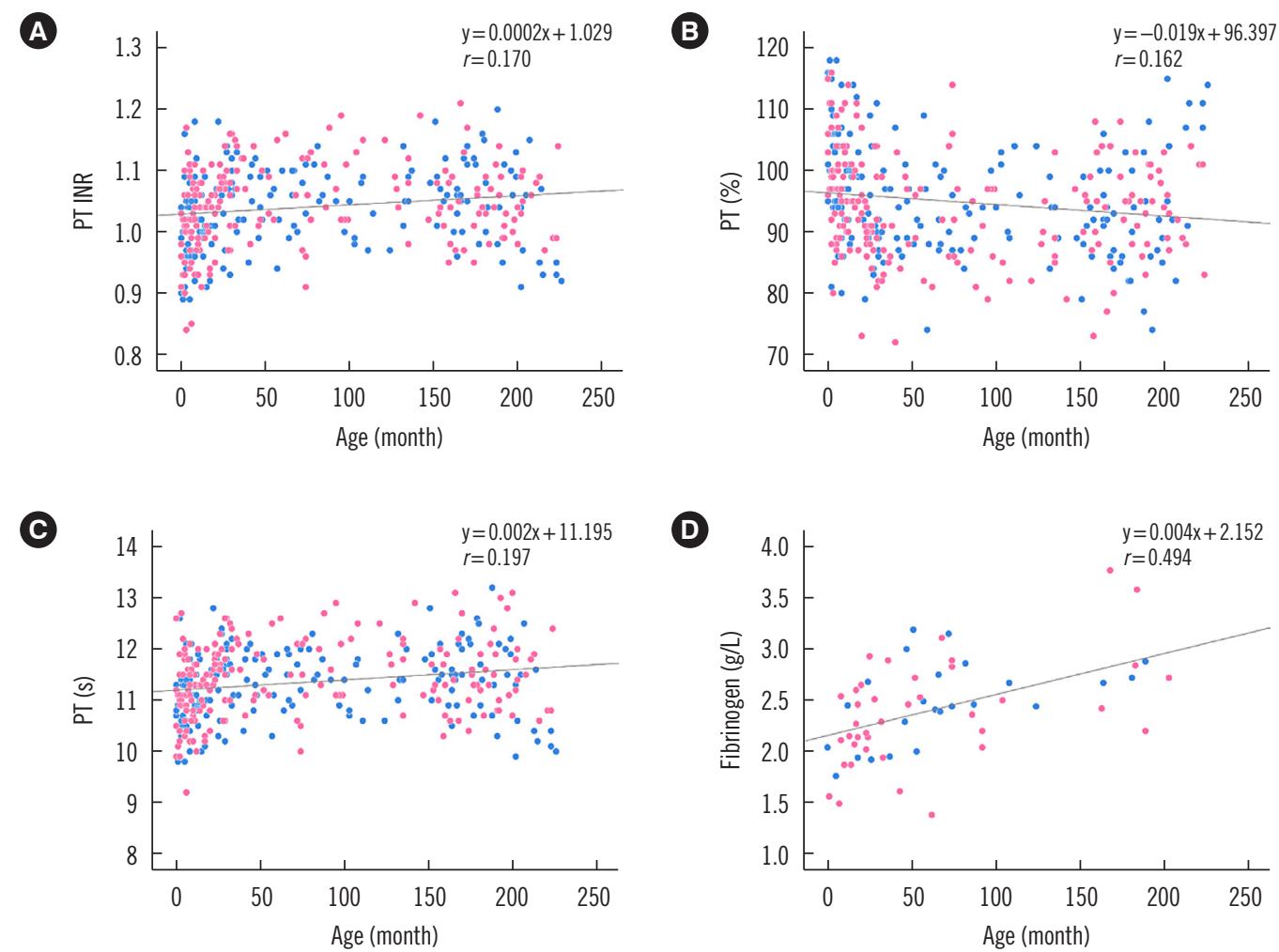

Fig. 2. Scatter plots of coagulation test results showing age-dependent changes. Results obtained at SNUH using the ACL TOP analyzer (Instrumentation Laboratory, Bedford, MA, USA) after outlier exclusion are presented. (A-D) PT INR, PT percentage, PT, and fibrinogen. Blue and red dots represent male and female children enrolled in the present study. The gray line represents the trend line; its equation and $r$ value are given.

Abbreviations: SNUH, Seoul National University Hospital; PT, prothrombin time; INR, international normalized ratio.

of authoritative pediatric reference intervals. While we did select "presumed healthy" patients on the basis of medical record review, various statistical techniques are available to extract "healthy" population data from a mixed dataset using visualization or formulation, under the assumption that the reference values from the healthy population have a near-Gaussian distribution [21].

Age-specific reference intervals were required for most tests, except glucose, cholesterol, albumin, bilirubin, $\mathrm{Cl}$, and CRP, which did not require any partitioning. Age partitioning of children younger or older than 3 months for Na was confirmed only in the multicenter analysis, which included a larger sample size than the single-center analysis. Sex-specific reference intervals were established for $\mathrm{P}$, uric acid, protein, ALP, AST, and $\mathrm{Cr}$ in some age-partitioned subgroups, and for $\mathrm{K}$ only in the multicenter analysis. Generally, reference intervals were more strongly affected by age than by sex, which is in line with findings in previous studies [7, 8, 24, 32]. However, the influence of sex on the reference intervals in the present study was not significant or substantially smaller than that in previous studies $[7,8]$. For example, the reference intervals for calcium, BUN, cholesterol, albumin, bilirubin, and ALT were affected by sex in at least one age-partitioned subgroup in these previous studies, whereas we did not observe an effect of sex for these tests. This may be due to the relatively small sample sizes of the sex-partitioned subgroups, thus reducing statistical power, or due to age-partitioning based on chronological age regardless of individual growth and sexual development, such as the Tanner stage.

Age-dependent increasing tendencies were observed for segmented neutrophil count, hemoglobin, hematocrit, BUN, uric acid, and $\mathrm{Cr}$, whereas decreasing tendencies were observed for WBC count, lymphocyte percentage, platelets, P, and K. Age-dependent increasing tendencies for $\mathrm{Cr}$, uric acid, and decreasing tendencies for $\mathrm{P}$ have been observed in previous studies $[8,15$, 28]. Figs. 1, 2, and 3 show age-dependent changes in pediatric laboratory test results, which can lead to misinterpretation of "abnormal" results from pediatric patients as "normal" in reference to adult intervals or vice versa. Thus, adult reference intervals are inappropriate for interpreting results of pediatric patients.

Despite the best efforts to minimize disparities among plat- 
Sung JY, et al.

Pediatric reference intervals in Korean population

A

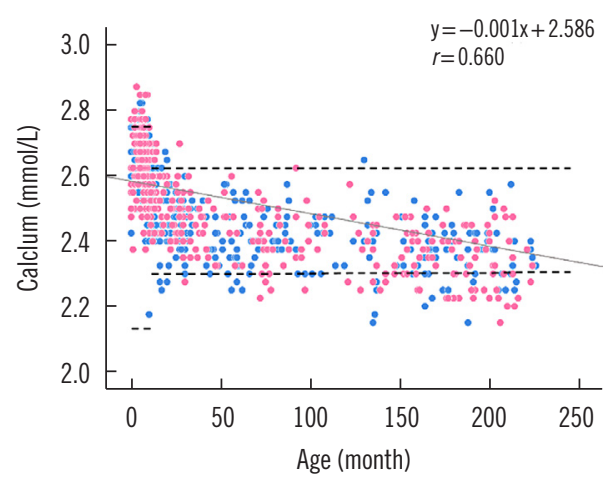

C

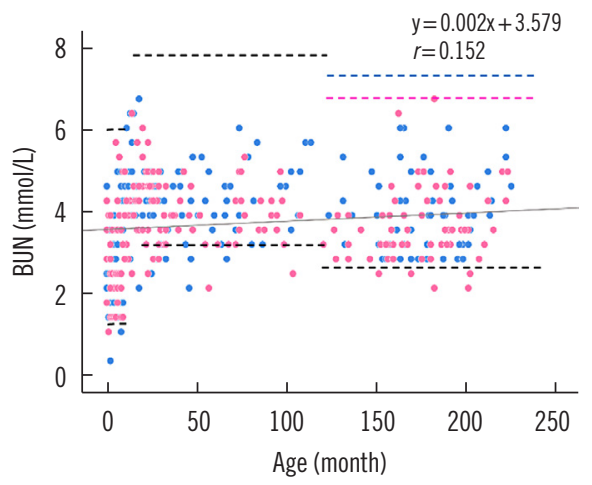

E

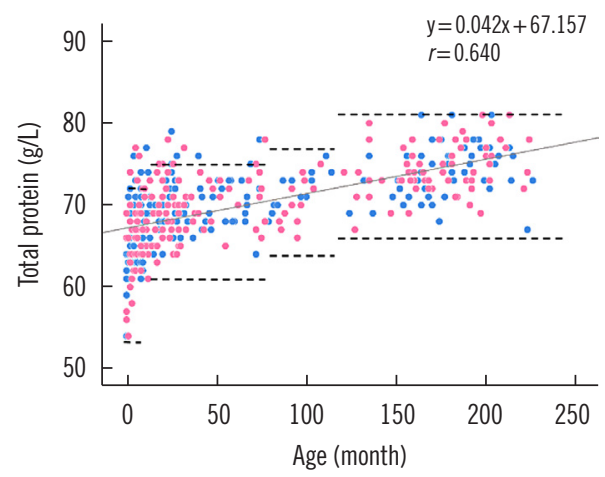

G

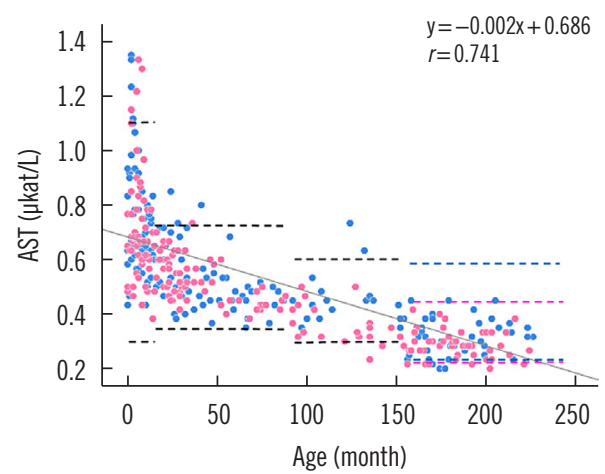

B

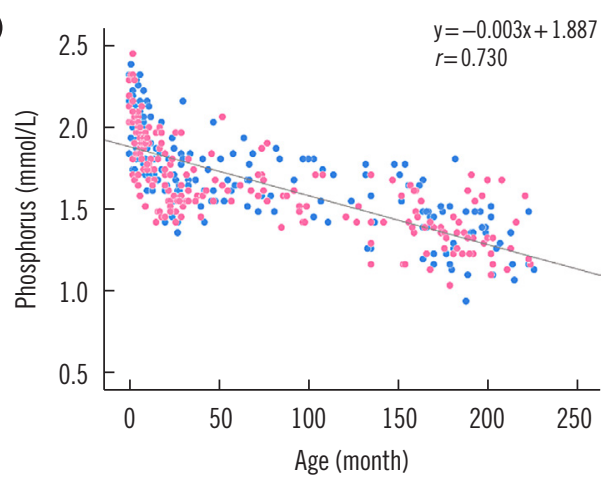

D

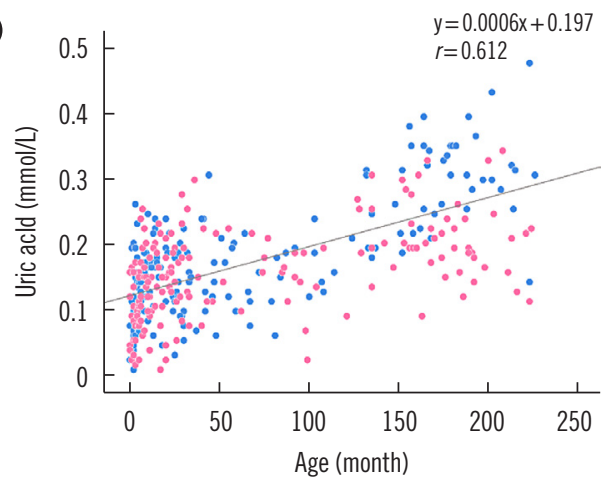

F

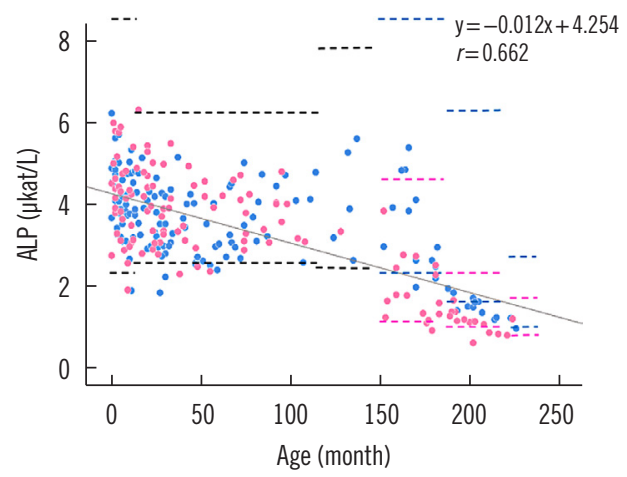

$\boldsymbol{\Theta}$

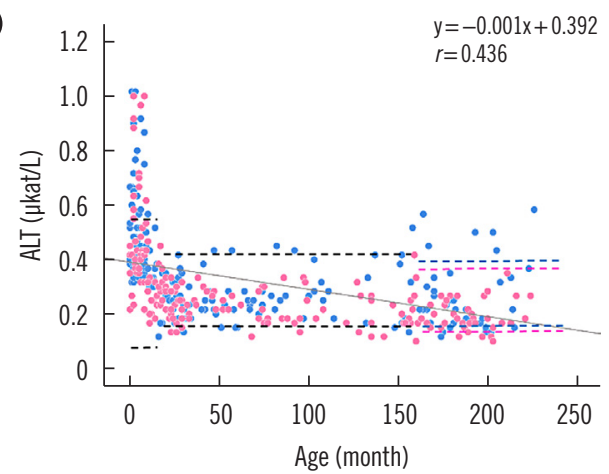

Fig. 3. Scatter plots of clinical chemistry results showing age-dependent changes. Reference intervals established in a previous study based mainly on a Caucasian population [8] are indicated as horizontal dashed lines. All test results that passed method comparison, considered mergeable, and subsequently used in multicenter analysis are plotted. (A-H) Calcium, phosphorus, BUN, uric acid, total protein, ALP, AST, and ALT.

(Continued to the next page) 

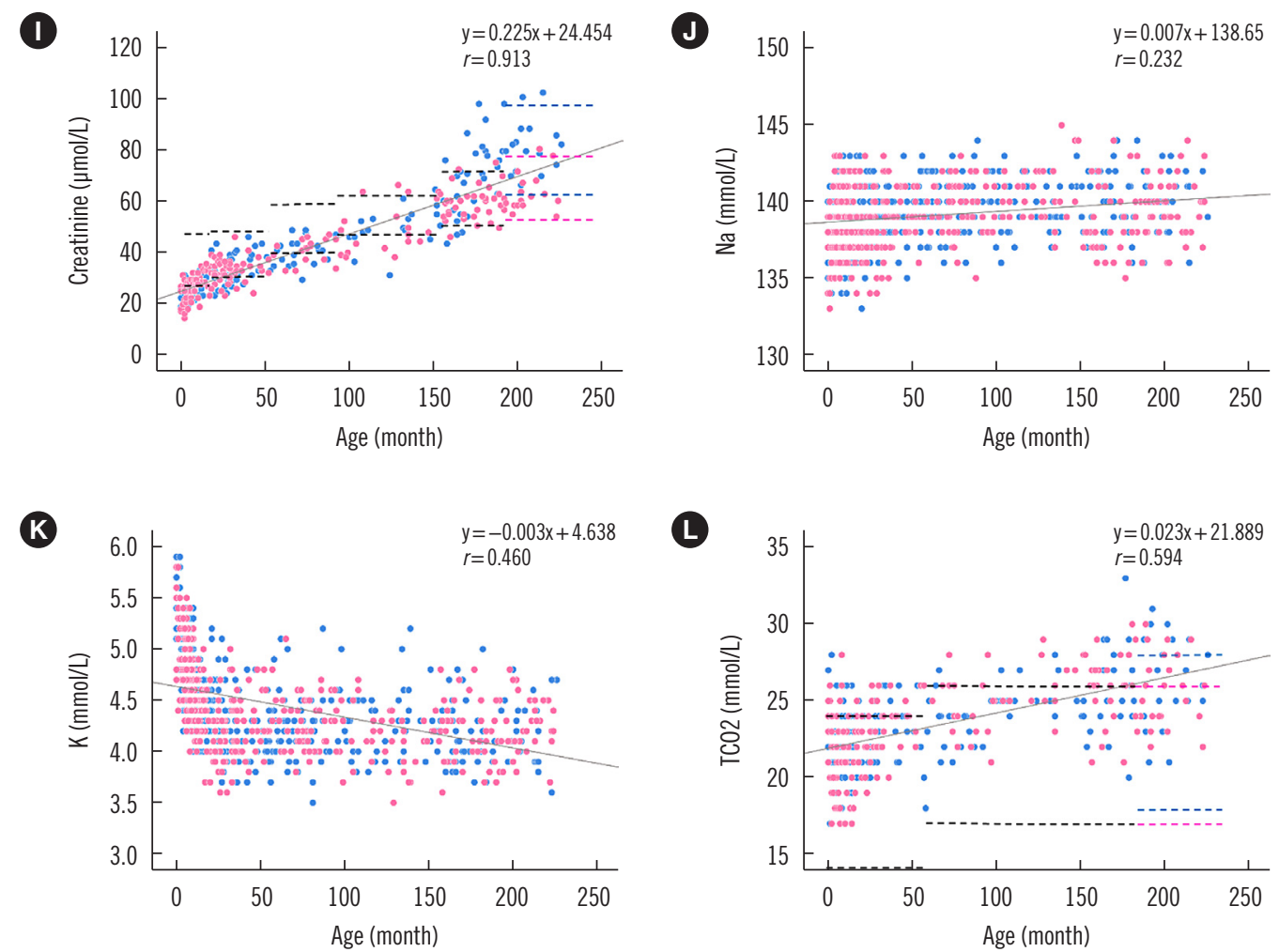

Fig. 3. Continued. (I-L), creatinine, sodium, potassium, and TCO2. Blue and red dots represent male and female children enrolled in the present study. Blue, red, and black dashed lines represent male, female, and common reference limits established in a previous study, respectively. The gray line represents the trend line; its equation and $r$ value are given.

Abbreviations: BUN, blood urea nitrogen; ALP alkaline phosphatase; AST, aspartate aminotransferase; ALT, alanine aminotransferase.

forms and methods, previous studies have reported such disparities arising from differences in instruments and testing principles used [5, 8], suggesting the necessity of establishing platform- or methodology-specific reference intervals. Our study was initially designed as a multicenter trial for the establishment of Korean pediatric reference intervals, which generally are applicable to all analytical platforms. However, based on a method comparison, only items that showed sufficient comparability of test methods were included in the multicenter reference interval analysis. This difference between instruments may have contributed to the loss of ethnical influence like lower ALT level in the Asian population that was revealed in a previous study but not observed in our study (Table 3). Therefore, the reference intervals determined in the present study are valid only for specific platforms (hematology testing using Sysmex XE-2100, coagulation testing using ACL TOP, and chemistry testing using TBA-c16000) and the availability can be limited now because one of the platforms, Sysmex XE-2100 has been discontinued. However, some chemistry test results were highly equivalent to those obtained from TBA-c16000 and thus can be transferred to other platforms after validation.

The transferability of CALIPER reference intervals established using one platform to other platforms even if $r^{2}$ is smaller than 0.95 has been previously assessed using statistical methods such as Deming regression rather than simple linear regression when $r^{2}$ is larger than 0.70 [34]. Further, research groups have attempted to transfer CALIPER reference intervals to their own platform in practical trials $[35,36]$. We assessed method comparability of different platforms using the protocol suggested in the CLSI EP09-A3 guidelines [37], which revealed a high correlation among the platforms, as shown in Supplemental Data Table S3. Thus, although results of a limited number of test items could be combined to determine pediatric reference intervals, most pediatric reference intervals for chemistry tests established in the present study can be adopted by other laboratories and utilized for patient evaluation after adequate validation [2], without the need for establishing institution-specific reference intervals.

Our study had some limitations. As a retrospective study, data were not obtained in a well-controlled condition. For example, blood samples for preoperative tests had not been taken under 
strictly controlled conditions considering diet or a fasting period, which might have affected the results of certain tests. Therefore, the influence of these factors cannot be completely excluded, although one study interpreted this characteristic of indirect sampling to well reflect "routine" pre-analytical and analytical conditions [33]. Additionally, the small sizes of some subgroups might have led to analytical inaccuracies despite the application of robust statistical methods. Although the analytical approach we used was developed to allow for establishing reliable reference intervals for small reference groups, broadening of the $\mathrm{Cl}$ for the upper and lower reference limits is inevitable. In practice, lower reference limits of some tests or the $90 \% \mathrm{Cl}$ of those determined using the robust method showed negative values because of a small subgroup size. Sample size affects not only statistical power but also subgroup partitioning per se. As shown in Table 3 , in the CALIPER study, age-specific reference intervals were established for the early neonatal period (0-14 days). However, we could not establish reference intervals for this age group, as our study did not include reference individuals of this age.

Further, the method comparison test was performed only for clinical chemistry tests on the platforms used in the participating hospitals (TBA-c16000, AU 5800, COBAS 8000, and Hitachi 7600). Therefore, hematology and coagulation test results from other instruments were unavailable to establish multicenter reference intervals by merging with those obtained from Sysmex XE 2100 and ACL TOP, although some tests showed comparable results in the diagnostic hematology program of Korean Association of External Quality Assessment (Supplemental Data Table S4) and Mann-Whitney U test (Supplemental Data Table S5). In addition, chemistry test results from other platforms that were not standardized or harmonized cannot be combined for analysis, even if the comparison test showed acceptable equivalence.

Considering the limitations of the present study, future studies designed in a prospective manner with direct reference individual sampling based on healthy community children with a larger sample size, strict control of the sample collection condition, and matching platforms between hospitals are required to establish reliable pediatric reference intervals.

\section{ACKNOWLEDGMENTS}

We thank the CALIPER team for advice on statistical analysis.

\section{AUTHOR CONTRIBUTIONS}

JY Sung and JD Seo drafted the manuscript. JY Sung, DH Ko,
MJ Park, and SM Hwang acquired data from each institution. JY Sung, JD Seo, and S Oh analyzed the data and interpreted the results. JY Sung, MJ Park, S Chun, MW Seong, J Song, SH Song, and SS Park designed the study. JD Seo and SH Song revised and approved the final manuscript. All authors reviewed the manuscript and provided critical feedback.

\section{CONFLICTS OF INTEREST}

None declared.

\section{RESEARCH FUNDING}

This study was supported by the Quality Improvement Research Fund of the Laboratory Medicine Foundation (LMF) in 2014.

\section{ORCID}

Ji Yeon Sung https://orcid.org/0000-0003-2743-3220

Jong Do Seo https://orcid.org/0000-0001-7449-7978

Dae-Hyun Ko https://orcid.org/0000-0002-9781-0928 Min-Jeong Park https://orcid.org/0000-0002-2775-2128 Sang Mee Hwang https://orcid.org/0000-0003-3390-1932 Sohee Oh

Sail Chun Moon-Woo Seong Junghan Song Sang Hoon Song Sung Sup Park https://orcid.org/0000-0002-3010-448X https://orcid.org/0000-0002-5792-973X https://orcid.org/0000-0003-2954-3677 https://orcid.org/0000-0003-0576-9938 https://orcid.org/0000-0002-5084-1137 https://orcid.org/0000-0003-3754-4848

\section{REFERENCES}

1. Horn PS and Pesce AJ. Reference intervals: an update. Clin Chim Acta 2003;334:5-23.

2. CLSI. Defining, establishing, and verifying reference intervals in the clinical laboratory; approved guideline. Third ed. CLSI EP28-A3c. Wayne, PA: Clinical Laboratory Standards Institute. 2010.

3. Jung B and Adeli K. Clinical laboratory reference intervals in pediatrics: the CALIPER initiative. Clin Biochem 2009;42:1589-95.

4. Schnabl K, Chan MK, Adeli K. 3. Pediatric reference intervals: critical gap analysis and establishment of a national initiative. EJIFCC 2008;19: 115-22.

5. Schnabl K, Chan MK, Gong Y, Adeli K. Closing the gaps in paediatric reference intervals: the CALIPER initiative. Clin Biochem Rev 2008;29: 89-96.

6. Adeli K. Closing the gaps in pediatric reference intervals: the CALIPER initiative. Clin Biochem 2011;44:480-2.

7. Chan MK, Seiden-Long I, Aytekin M, Quinn F, Ravalico T, Ambruster D, et al. Canadian Laboratory Initiative on Pediatric Reference Interval Database (CALIPER): pediatric reference intervals for an integrated clinical 
chemistry and immunoassay analyzer, Abbott ARCHITECT ci8200. Clin Biochem 2009;42:885-91.

8. Colantonio DA, Kyriakopoulou L, Chan MK, Daly CH, Brinc D, Venner $\mathrm{AA}$, et al. Closing the gaps in pediatric laboratory reference intervals: a CALIPER database of 40 biochemical markers in a healthy and multiethnic population of children. Clin Chem 2012;58:854-68.

9. Kohse KP and Thamm M. KiGGS - the German survey on children's health as data base for reference intervals. Clin Biochem 2011;44:479.

10. Kurth BM, Kamtsiuris P, Hölling H, Schlaud M, Dölle R, Ellert $U$, et al. The challenge of comprehensively mapping children's health in a nation-wide health survey: design of the German KiGGS-Study. BMC Public Health 2008;8:196.

11. Flanders MM, Crist RA, Roberts WL, Rodgers GM. Pediatric reference intervals for seven common coagulation assays. Clin Chem 2005;51: 1738-42.

12. Clifford SM, Bunker AM, Jacobsen JR, Roberts WL. Age and gender specific pediatric reference intervals for aldolase, amylase, ceruloplasmin, creatine kinase, pancreatic amylase, prealbumin, and uric acid. Clin Chim Acta 2011;412:788-90.

13. Bailey D, Colantonio D, Kyriakopoulou L, Cohen AH, Chan MK, Armbruster D, et al. Marked biological variance in endocrine and biochemical markers in childhood: establishment of pediatric reference intervals using healthy community children from the CALIPER cohort. Clin Chem 2013;59:1393-405.

14. Tahmasebi H, Asgari S, Hall A, Higgins V, Chowdhury A, Thompson R, et al. Influence of ethnicity on biochemical markers of health and disease in the CALIPER cohort of healthy children and adolescents. Clin Chem Lab Med 2019;58:605-17.

15. Cho SM, Lee SG, Kim HS, Kim JH. Establishing pediatric reference intervals for 13 biochemical analytes derived from normal subjects in a pediatric endocrinology clinic in Korea. Clin Biochem 2014;47:268-71.

16. Nah EH, Kim S, Cho S, Cho HI.Nah EH. Complete Blood Count Reference Intervals and Patterns of Changes Across Pediatric, Adult, and Geriatric Ages in Korea. Ann Lab Med 2018;38:503-511.

17. Lee HR, Shin S, Yoon JH, Roh EY, Chang JY. Reference Intervals of Hematology and Clinical Chemistry Analytes for 1-Year-Old Korean Children. Ann Lab Med 2016;36:481-8.

18. Kim B, Lee MN, Park HD, Kim JW, Chang YS, Park WS, Lee SY. Dried blood spot testing for seven steroids using liquid chromatography-tandem mass spectrometry with reference interval determination in the Korean population. Ann Lab Med 2015;35:578-85.

19. Ceriotti F. Establishing pediatric reference intervals: a challenging task. Clin Chem 2012;58:808-10.

20. Shaw JL, Binesh Marvasti T, Colantonio D, Adeli K. Pediatric reference intervals: challenges and recent initiatives. Crit Rev Clin Lab Sci 2013; 50:37-50.

21. Farrell $C L$ and Nguyen L. Indirect reference intervals: harnessing the power of stored laboratory data. Clin Biochem Rev 2019;40:99-111.

22. Beck GR, Sullivan EC, Moran E, Zerler B. Relationship between alkaline phosphatase levels, osteopontin expression, and mineralization in dif- ferentiating MC3T3-E1 osteoblasts. J Cell Biochem 1998;68:269-80.

23. Stein GS, Lian JB, Owen TA. Relationship of cell growth to the regulation of tissue-specific gene expression during osteoblast differentiation. FASEB J 1990;4:3111-23.

24. Clifford SM, Bunker AM, Jacobsen JR, Roberts WL. Age and gender specific pediatric reference intervals for aldolase, amylase, ceruloplasmin, creatine kinase, pancreatic amylase, prealbumin, and uric acid. Clin Chim Acta 2011;412:788-90.

25. Bureau International des Poids et Mesures. JCTLM database: laboratory medicine and in vitro diagnostics. https://www.bipm.org/jctlm/ (Updated on Jan 2020)

26. Solberg HE and Lahti A. Detection of outliers in reference distributions: performance of Horn's algorithm. Clin Chem 2005;51:2326-32.

27. Horn PS, Pesce AJ, Copeland BE. A robust approach to reference interval estimation and evaluation. Clin Chem 1998;44:622-31.

28. Shaw JL, Cohen A, Konforte D, Binesh-Marvasti T, Colantonio DA, Adeli K. Validity of establishing pediatric reference intervals based on hospital patient data: a comparison of the modified Hoffmann approach to CALIPER reference intervals obtained in healthy children. Clin Biochem 2014;47:166-72.

29. Solberg HE. Using a hospitalized population to establish reference intervals: pros and cons. Clin Chem 1994;40:2205-6.

30. Arzideh F, Brandhorst G, Gurr E, Hinsch W, Hoff T, Roggenbuck L, et al. An improved indirect approach for determining reference limits from intra-laboratory data bases exemplified by concentrations of electroIytes. J Lab Med 2009;33:52-66.

31. Hoffmann RG. Statistics in the practice of medicine. JAMA 1963;185: 864-73.

32. Zierk J, Arzideh F, Rechenauer T, Haeckel R, Rascher W, Metzler M, et al. Age- and sex-specific dynamics in 22 hematologic and biochemical analytes from birth to adolescence. Clin Chem 2015;61:964-73.

33. Jones GRD, Haeckel R, Loh TP, Sikaris K, Streichert T, Katayev A, et al. Indirect methods for reference interval determination-review and recommendations. Clin Chem Lab Med 2018;57:20-9.

34. Estey MP, Cohen AH, Colantonio DA, Chan MK, Marvasti TB, Randell E, et al. CLSI-based transference of the CALIPER database of pediatric reference intervals from Abbott to Beckman, Ortho, Roche and Siemens Clinical Chemistry Assays: direct validation using reference samples from the CALIPER cohort. Clin Biochem 2013;46:1197-219.

35. Araújo PA, Thomas D, Sadeghieh T, Bevilacqua V, Chan MK, Chen Y, et al. CLSI-based transference of the CALIPER database of pediatric reference intervals to Beckman Coulter DxC biochemical assays. Clin Biochem 2015;48:870-80.

36. Abou El Hassan M, Stoianov A, Araújo PA, Sadeghieh T, Chan MK, Chen $\mathrm{Y}$, et al. CLSI-based transference of CALIPER pediatric reference intervals to Beckman Coulter AU biochemical assays. Clin Biochem 2015;48:1151-9.

37. CLSI. Measurement procedure comparison and bias estimation using patient samples; approved guideline. Third ed. CLSI EP09-A3. Wayne, PA: Clinical Laboratory Standards Institute. 2013. 
Sung JY, et al.

Pediatric reference intervals in Korean population

Supplemental Data Table S1. Distribution of the study participants from the four hospitals before outlier exclusion and method comparison, sorted by age group and sex $(\mathrm{N}=1,031)$

\begin{tabular}{|c|c|c|c|c|c|c|c|c|}
\hline \multirow{2}{*}{ Age } & \multicolumn{2}{|c|}{ SNUH } & \multicolumn{2}{|c|}{ AMC } & \multicolumn{2}{|c|}{ SNUBH } & \multicolumn{2}{|c|}{ KSHH } \\
\hline & Male & Female & Male & Female & Male & Female & Male & Female \\
\hline 0-3 mo & 18 & 17 & 1 & 4 & 3 & 1 & 0 & 0 \\
\hline 4-11 mo & 35 & 35 & 87 & 73 & 14 & 7 & 4 & 3 \\
\hline $1-6 \mathrm{yr}$ & 75 & 73 & 60 & 35 & 68 & 56 & 28 & 20 \\
\hline $7-12 \mathrm{yr}$ & 23 & 26 & 9 & 7 & 33 & 20 & 11 & 12 \\
\hline $13-15$ yr & 27 & 35 & 5 & 6 & 10 & 4 & 7 & 7 \\
\hline $16-18 \mathrm{yr}$ & 18 & 19 & 5 & 10 & 4 & 8 & 4 & 4 \\
\hline
\end{tabular}

Abbreviations: SNUH, Seoul National University Hospital; AMC, Asan Medical Center; SNUBH, Seoul National University Bundang Hospital; KSHH, Kangnam Sacred Heart Hospital; mo, month; yr, year. 
Supplemental Data Table S2. Results of method comparison using Deming regression, compared with the comparative method, TBAc16000

\begin{tabular}{|c|c|c|c|c|c|c|c|c|}
\hline \multirow{3}{*}{ Test method } & \multirow{3}{*}{ Analyte } & \multicolumn{3}{|c|}{ Slope } & \multicolumn{3}{|c|}{ Intercept } & \multirow{3}{*}{ Correlation (r) } \\
\hline & & & \multicolumn{2}{|c|}{$95 \% \mathrm{Cl}$} & & \multicolumn{2}{|c|}{$95 \% \mathrm{Cl}$} & \\
\hline & & & Lower & Upper & & Lower & Upper & \\
\hline \multirow[t]{17}{*}{ Cobas 8000} & Albumin & 1.15 & 1.08 & 1.22 & -0.87 & -1.14 & -0.60 & 0.979 \\
\hline & ALP & 1.00 & 0.99 & 1.00 & 4.28 & 3.21 & 5.36 & $>0.999$ \\
\hline & ALT & 0.93 & 0.92 & 0.94 & -2.76 & -3.32 & -2.20 & $>0.999$ \\
\hline & AST & 0.93 & 0.93 & 0.93 & -0.11 & -0.90 & 0.68 & $>0.999$ \\
\hline & Bilirubin, total & 1.03 & 1.02 & 1.04 & -0.21 & -0.24 & -0.17 & $>0.999$ \\
\hline & BUN & 0.99 & 0.98 & 1.00 & -0.46 & -0.81 & -0.11 & $>0.999$ \\
\hline & Calcium & 0.98 & 0.95 & 1.01 & 0.20 & -0.08 & 0.48 & 0.994 \\
\hline & Chloride & 0.95 & 0.88 & 1.03 & 2.22 & -5.24 & 9.69 & 0.966 \\
\hline & Cholesterol & 1.01 & 0.99 & 1.03 & -3.99 & -7.75 & -0.24 & 0.997 \\
\hline & Creatinine & 0.98 & 0.97 & 0.98 & 0.01 & -0.01 & 0.03 & $>0.999$ \\
\hline & Glucose & 1.01 & 0.99 & 1.03 & -0.26 & -2.68 & 2.16 & 0.998 \\
\hline & Phosphorus & 1.00 & 0.97 & 1.03 & 0.05 & -0.07 & 0.15 & 0.996 \\
\hline & Potassium & 1.00 & 0.97 & 1.02 & 0.06 & -0.07 & 0.19 & 0.995 \\
\hline & Protein & 0.96 & 0.93 & 0.99 & 0.03 & -0.19 & 0.26 & 0.993 \\
\hline & Sodium & 1.06 & 0.96 & 1.17 & -8.02 & -22.64 & 6.61 & 0.941 \\
\hline & TC02 & 0.91 & 0.87 & 0.95 & 1.11 & 0.18 & 2.04 & 0.989 \\
\hline & Uric acid & 0.92 & 0.91 & 0.93 & -0.10 & -0.18 & -0.03 & 0.999 \\
\hline \multirow[t]{17}{*}{ Hitachi 7600} & Albumin & 0.93 & 0.86 & 0.99 & 0.16 & -0.10 & 0.43 & 0.969 \\
\hline & ALP & 1.12 & 1.11 & 1.12 & 6.60 & 4.90 & 8.40 & $>0.999$ \\
\hline & ALT & 0.97 & 0.96 & 0.99 & -1.60 & -2.80 & -0.30 & 0.999 \\
\hline & AST & 1.01 & 1.01 & 1.01 & -0.60 & -1.10 & 0.00 & 1.000 \\
\hline & Bilirubin, total & 1.05 & 1.04 & 1.06 & -0.07 & -0.10 & -0.05 & $>0.999$ \\
\hline & BUN & 1.06 & 1.04 & 1.08 & -0.35 & -0.90 & 0.20 & 0.999 \\
\hline & Calcium & 1.01 & 0.93 & 1.09 & -0.06 & -0.81 & 0.69 & 0.960 \\
\hline & Chloride & 0.91 & 0.84 & 0.98 & 7.26 & -0.01 & 14.53 & 0.965 \\
\hline & Cholesterol & 0.98 & 0.93 & 1.04 & -3.30 & -12.50 & 5.90 & 0.983 \\
\hline & Creatinine & 0.94 & 0.93 & 0.94 & 0.01 & -0.01 & 0.03 & $>0.999$ \\
\hline & Glucose & 1.04 & 1.01 & 1.07 & -4.10 & -8.10 & -0.10 & 0.995 \\
\hline & Phosphorus & 1.00 & 0.97 & 1.03 & 0.05 & -0.07 & 0.15 & 0.996 \\
\hline & Potassium & 0.96 & 0.94 & 0.98 & 0.26 & 0.16 & 0.36 & 0.997 \\
\hline & Protein & 1.04 & 1.01 & 1.06 & -0.44 & -0.62 & -0.26 & 0.996 \\
\hline & Sodium & 1.07 & 0.99 & 1.16 & -8.59 & -20.84 & 3.66 & 0.959 \\
\hline & TCO2 & 0.81 & 0.72 & 0.89 & 0.97 & -1.12 & 3.07 & 0.928 \\
\hline & Uric acid & 0.94 & 0.92 & 0.96 & 0.17 & 0.07 & 0.27 & 0.998 \\
\hline \multirow[t]{4}{*}{ AU 5800} & Albumin & 1.01 & 0.97 & 1.06 & -0.26 & -0.46 & -0.07 & 0.986 \\
\hline & ALP & 1.15 & 1.12 & 1.18 & 1.20 & -3.90 & 6.30 & 0.997 \\
\hline & ALT & 0.99 & 0.98 & 1.00 & -0.70 & -1.40 & 0.00 & $>0.999$ \\
\hline & AST & 1.09 & 1.08 & 1.09 & -0.70 & -1.70 & 0.20 & $>0.999$ \\
\hline
\end{tabular}


Sung JY, et al.

Pediatric reference intervals in Korean population

Supplemental Data Table S2. Continued

\begin{tabular}{|c|c|c|c|c|c|c|c|c|}
\hline \multirow{3}{*}{ Test method } & \multirow{3}{*}{ Analyte } & \multicolumn{3}{|c|}{ Slope } & \multicolumn{3}{|c|}{ Intercept } & \multirow{3}{*}{ Correlation $(r)$} \\
\hline & & & \multicolumn{2}{|c|}{$95 \% \mathrm{Cl}$} & & \multicolumn{2}{|c|}{$95 \% \mathrm{Cl}$} & \\
\hline & & & Lower & Upper & & Lower & Upper & \\
\hline & Bilirubin, total & 1.12 & 1.10 & 1.13 & -0.03 & -0.09 & 0.02 & 0.999 \\
\hline & BUN & 1.03 & 1.01 & 1.05 & -0.40 & -1.00 & 0.10 & 0.999 \\
\hline & Calcium & 0.86 & 0.80 & 0.92 & 0.87 & 0.35 & 1.39 & 0.974 \\
\hline & Chloride & 1.00 & 0.95 & 1.05 & 0.60 & -4.80 & 5.90 & 0.984 \\
\hline & Cholesterol & 1.05 & 1.01 & 1.09 & -14.30 & -21.20 & -7.40 & 0.992 \\
\hline & Creatinine & 1.04 & 1.03 & 1.05 & -0.09 & -0.12 & -0.05 & $>0.999$ \\
\hline & Glucose & 1.03 & 1.01 & 1.05 & -3.40 & -6.30 & -0.50 & 0.997 \\
\hline & Phosphorus & 1.01 & 0.97 & 1.04 & -0.05 & -0.18 & 0.09 & 0.994 \\
\hline & Potassium & 0.98 & 0.95 & 1.01 & 0.06 & -0.08 & 0.20 & 0.994 \\
\hline & Protein & 0.98 & 0.95 & 1.02 & -0.22 & -0.46 & 0.03 & 0.992 \\
\hline & Sodium & 1.08 & 0.99 & 1.17 & -12.00 & -24.60 & 0.60 & 0.957 \\
\hline & TCO2 & 1.00 & 0.94 & 1.07 & -4.00 & -5.50 & -2.40 & 0.974 \\
\hline & Uric acid & 0.94 & 0.92 & 0.96 & 0.17 & 0.07 & 0.27 & 0.998 \\
\hline
\end{tabular}

Abbreviations: ALP, alkaline phosphatase; ALT, alanine aminotransferase; AST, aspartate aminotransferase; $\mathrm{BUN}$, blood urea nitrogen; TCO2, total $\mathrm{CO}_{2}$. 
Supplemental Data Table S3. Instruments, reagents, and calibrators used in the four hospitals for routine chemistry tests that showed an equivalent result in at least one hospital when compared with SNUH and for which standardization or harmonization was confirmed by JCTLM

\begin{tabular}{|c|c|c|c|c|}
\hline Institute & SNUH & SNUBH & AMC & KSHH \\
\hline Instrument & TBA-c16000 & AU 5800 & Cobas 8000 & Hitachi 7600 \\
\hline \multirow[t]{3}{*}{ Calcium } & Denka & Beckman Coulter & Roche & Wako \\
\hline & Roche C.f.a.s & Beckman Coulter system calibrator & Roche C.f.a.s & Roche C.f.a.s \\
\hline & NIST SRM 915a & NIST SRM 909b & SRM 956c & SRM 956c \\
\hline \multirow[t]{3}{*}{ Glucose } & SICDIA & Beckman Coulter & Roche & Wako \\
\hline & Roche C.f.a.s & Beckman Coulter system calibrator & Roche C.f.a.s & Roche C.f.a.s \\
\hline & NIST SRM 965 & NIST SRM 965 & NIST SRM 965 & NIST SRM 965 \\
\hline \multirow[t]{3}{*}{ Cholesterol } & SICDIA & Beckman Coulter & Roche & Wako \\
\hline & Roche C.f.a.s & Beckman Coulter system calibrator & Roche C.f.a.s & Roche C.f.a.s \\
\hline & Unidentified & Unidentified & Unidentified & Unidentified \\
\hline \multirow[t]{3}{*}{ Sodium } & Toshiba & Beckman Coulter & Roche & Sekisui \\
\hline & Toshiba C.f.a.s & Beckman Coulter ISE standard & Roche ISE STD & Sekisui ISE standard \\
\hline & NIST SRM 919 & NIST SRM 919 & Primary calibrator & Unidentified \\
\hline \multirow[t]{3}{*}{ Potassium } & Toshiba & Beckman Coulter & Roche & Sekisui \\
\hline & Toshiba C.f.a.s & Beckman Coulter ISE standard & Roche ISE STD & Sekisui ISE standard \\
\hline & NIST SRM 919 & NIST SRM 918 & Primary calibrator & Unidentified \\
\hline \multirow[t]{3}{*}{ Chloride } & Toshiba & Beckman Coulter & Roche & Sekisui \\
\hline & Toshiba C.f.a.s & Beckman Coulter ISE standard & Roche ISE STD & Sekisui ISE standard \\
\hline & NIST SRM 919 & NIST SRM 919 & Primary calibrator & Unidentified \\
\hline
\end{tabular}

Abbreviations: JCTLM, Joint Committee for Traceability in Laboratory Medicine; C.f.a.s, Calibrator for Automated Systems; NIST, National Institute of Standards and Technology; SRM, standard reference material; SNUH, Seoul National University Hospital; SNUBH, Seoul National University Bundang Hospital; AMC, Asan Medical Center; KSHH, Kangnam Sacred Heart Hospital. 
Sung JY, et al.

Pediatric reference intervals in Korean population

Supplemental Data Table S4. Results of the diagnostic hematology program of the Korean Association of External Quality Assessment from 2012 to 2015, during the period of data collection

\begin{tabular}{|c|c|c|c|c|c|c|c|c|c|c|}
\hline \multirow{2}{*}{ Sample } & \multirow{2}{*}{ Test } & \multirow{2}{*}{ Mean* } & \multicolumn{2}{|c|}{ SNUH } & \multicolumn{2}{|c|}{ AMC } & \multicolumn{2}{|c|}{ SNUBH } & \multicolumn{2}{|c|}{ KSHH } \\
\hline & & & Value & SDI* & Value & SDI & Value & SDI & Value & SDI \\
\hline \multirow[t]{5}{*}{2012011} & WBC $\left(\times 10^{9} / L\right)$ & 7.83 & 8.00 & 0.29 & & & & & & \\
\hline & $\mathrm{RBC}\left(\times 10^{6} / \mu \mathrm{L}\right)$ & 4.70 & 4.78 & 0.06 & & & & & & \\
\hline & $\mathrm{Hb}(\mathrm{g} / \mathrm{L})$ & 134.6 & 136 & 0.49 & & & & & & \\
\hline & Hct (proportion of 1.0) & 0.41 & 0.42 & 0.91 & & & & & & \\
\hline & $\operatorname{PLT}\left(\times 10^{9} / \mathrm{L}\right)$ & 236.34 & 203 & -1.62 & & & & & & \\
\hline \multirow[t]{2}{*}{2012016} & PT INR & 2.87 & 2.43 & -0.83 & & & & & & \\
\hline & aPTा ratio & 2.19 & 2.10 & -0.13 & & & & & & \\
\hline \multirow[t]{5}{*}{2012021} & WBC $\left(\times 10^{9} / L\right)$ & 22.85 & 23.75 & 0.78 & & & & & & \\
\hline & $\mathrm{RBC}\left(\times 10^{6} / \mu \mathrm{L}\right)$ & 5.22 & 5.35 & 0.55 & & & & & & \\
\hline & $\mathrm{Hb}(\mathrm{g} / \mathrm{L})$ & 159.1 & 161 & 0.58 & & & & & & \\
\hline & Hct (proportion of 1.0) & 0.48 & 0.51 & 1.16 & & & & & & \\
\hline & $\operatorname{PLT}\left(\times 10^{9} / \mathrm{L}\right)$ & 457.56 & 408 & -1.03 & & & & & & \\
\hline \multirow[t]{5}{*}{2012031} & WBC $\left(\times 10^{9} / L\right)$ & 3.22 & 3.28 & 0.23 & 3.06 & -0.61 & & & & \\
\hline & $\mathrm{RBC}\left(\times 10^{6} / \mu \mathrm{L}\right)$ & 2.18 & 2.22 & 0.06 & 2.19 & 0.01 & & & & \\
\hline & $\mathrm{Hb}(\mathrm{g} / \mathrm{L})$ & 54.9 & 55 & 0.05 & 55 & 0.05 & & & & \\
\hline & Hct (proportion of 1.0) & 0.17 & 0.18 & 0.87 & 0.18 & 0.97 & & & & \\
\hline & $\operatorname{PLT}\left(\times 10^{9} / \mathrm{L}\right)$ & 76.01 & 69 & -0.96 & 72.00 & -0.55 & & & & \\
\hline \multirow[t]{2}{*}{2012036} & PT INR & 5.04 & 3.74 & -0.78 & 5.22 & 0.11 & & & & \\
\hline & aPT ratio & 3.53 & 3.41 & -0.03 & 2.73 & -0.83 & & & & \\
\hline \multirow[t]{5}{*}{2012041} & WBC $\left(\times 10^{9} / L\right)$ & 8.03 & 7.80 & -0.17 & 7.46 & -0.41 & & & & \\
\hline & $\mathrm{RBC}\left(\times 10^{6} / \mu \mathrm{L}\right)$ & 4.58 & 4.71 & 0.68 & 4.59 & 0.05 & & & & \\
\hline & $\mathrm{Hb}(\mathrm{g} / \mathrm{L})$ & 133.5 & 136 & 1.04 & 135 & 0.62 & & & & \\
\hline & Hct (proportion of 1.0) & 0.42 & 0.45 & 1.30 & 0.44 & 1.17 & & & & \\
\hline & $\operatorname{PLT}\left(\times 10^{9} / \mathrm{L}\right)$ & 238.27 & 231 & -0.33 & 218.00 & -0.91 & & & & \\
\hline \multirow[t]{5}{*}{2013011} & WBC $\left(\times 10^{9} / L\right)$ & 3.27 & 3.35 & 0.28 & 3.05 & -0.77 & & & & \\
\hline & $\mathrm{RBC}\left(\times 10^{6} / \mu \mathrm{L}\right)$ & 2.23 & 2.30 & 0.69 & 2.25 & 0.17 & & & & \\
\hline & $\mathrm{Hb}(\mathrm{g} / \mathrm{L})$ & 55.1 & 55 & -0.07 & 55 & -0.07 & & & & \\
\hline & Hct (proportion of 1.0) & 0.17 & 0.18 & 1.32 & 0.18 & 0.89 & & & & \\
\hline & $\operatorname{PLT}\left(\times 10^{9} / \mathrm{L}\right)$ & 69.72 & 63 & -0.86 & 61.00 & -1.11 & & & & \\
\hline \multirow[t]{2}{*}{2013016} & PT INR & 1.00 & 1.00 & 0.04 & 0.94 & -0.94 & & & & \\
\hline & aPTा ratio & 0.00 & 1.04 & 0.89 & 0.85 & -1.29 & & & & \\
\hline \multirow[t]{5}{*}{2013021} & WBC $\left(\times 10^{9} / L\right)$ & 8.02 & 8.24 & 0.33 & 7.65 & -0.57 & & & & \\
\hline & $\mathrm{RBC}\left(\times 10^{6} / \mu \mathrm{L}\right)$ & 4.63 & 4.73 & 0.27 & 4.59 & -0.12 & & & & \\
\hline & $\mathrm{Hb}(\mathrm{g} / \mathrm{L})$ & 131.7 & 134 & 0.87 & 132 & 0.12 & & & & \\
\hline & Hct (proportion of 1.0) & 0.40 & 0.42 & 1.05 & 0.42 & 0.80 & & & & \\
\hline & $\operatorname{PLT}\left(\times 10^{9} / \mathrm{L}\right)$ & 228.26 & 207.00 & -1.08 & 206.00 & -1.14 & & & & \\
\hline \multirow[t]{5}{*}{2013031} & WBC $\left(\times 10^{9} / L\right)$ & 23.04 & 24.31 & 0.86 & 21.68 & -0.92 & & & & \\
\hline & $\mathrm{RBC}\left(\times 10^{6} / \mu \mathrm{L}\right)$ & 5.25 & 5.14 & -0.09 & 5.08 & -0.14 & & & & \\
\hline & $\mathrm{Hb}(\mathrm{g} / \mathrm{L})$ & 161.9 & 160 & -0.55 & 159 & -0.85 & & & & \\
\hline & Hct (proportion of 1.0) & 0.47 & 0.46 & -0.44 & 0.47 & -0.06 & & & & \\
\hline & $\mathrm{PLT}\left(\times 10^{9} / \mathrm{L}\right)$ & 468.19 & 460.00 & -0.19 & 408.00 & -1.43 & & & & \\
\hline
\end{tabular}


Supplemental Data Table S4. Continued

\begin{tabular}{|c|c|c|c|c|c|c|c|c|c|c|}
\hline \multirow{2}{*}{ Sample } & \multirow{2}{*}{ Test } & \multirow{2}{*}{ Mean* } & \multicolumn{2}{|c|}{ SNUH } & \multicolumn{2}{|c|}{ AMC } & \multicolumn{2}{|c|}{ SNUBH } & \multicolumn{2}{|c|}{ KSHH } \\
\hline & & & Value & SDI* & Value & SDI & Value & SDI & Value & SDI \\
\hline \multirow[t]{2}{*}{2013036} & PT INR & 3.31 & 2.91 & -0.59 & 3.53 & 0.35 & & & & \\
\hline & aPTा ratio & 2.34 & 2.32 & -0.04 & 1.62 & -1.38 & & & & \\
\hline \multirow[t]{5}{*}{2013041} & WBC $\left(\times 10^{9} / L\right)$ & 8.04 & 8.25 & 0.39 & 7.88 & -0.28 & 7.79 & -0.45 & 7.80 & -0.43 \\
\hline & $\mathrm{RBC}\left(\times 10^{6} / \mu \mathrm{L}\right)$ & 4.69 & 4.70 & 0.06 & 4.70 & 0.06 & 4.67 & -0.14 & 4.67 & -0.14 \\
\hline & $\mathrm{Hb}(\mathrm{g} / \mathrm{L})$ & 134.6 & 135 & 0.14 & 136 & 0.53 & 134 & -0.25 & 135 & 0.14 \\
\hline & Hct (proportion of 1.0) & 0.41 & 0.41 & 0.08 & 0.43 & 0.76 & 0.43 & 0.76 & 0.38 & -1.35 \\
\hline & $\mathrm{PLT}\left(\times 10^{9} / \mathrm{L}\right)$ & 239.51 & 249.00 & 0.28 & 231.00 & -0.26 & 241.00 & 0.04 & 238.00 & -0.05 \\
\hline \multirow[t]{5}{*}{2014011} & WBC $\left(\times 10^{9} / \mathrm{L}\right)$ & 3.24 & 3.36 & 0.74 & 3.20 & -0.22 & 3.19 & -0.28 & 3.19 & -0.28 \\
\hline & $\mathrm{RBC}\left(\times 10^{6} / \mu \mathrm{L}\right)$ & 2.23 & 2.22 & -0.16 & 2.28 & 0.80 & 2.27 & 0.64 & 2.25 & 0.32 \\
\hline & $\mathrm{Hb}(\mathrm{g} / \mathrm{L})$ & 54.5 & 54 & -0.29 & 55 & 0.28 & 55 & 0.28 & 55 & 0.28 \\
\hline & Hct (proportion of 1.0) & 0.17 & 0.17 & 0.12 & 0.18 & 0.25 & 0.18 & 0.22 & 0.15 & -0.54 \\
\hline & $\mathrm{PLT}\left(\times 10^{9} / \mathrm{L}\right)$ & 76.63 & 73.00 & -0.15 & 71.00 & -0.24 & 72.00 & -0.20 & 75.00 & -0.07 \\
\hline \multirow[t]{2}{*}{2014016} & PT INR & 5.09 & 4.44 & -0.42 & 5.69 & 0.49 & 5.65 & 0.46 & 4.20 & -0.60 \\
\hline & aPTा (s) & 102.31 & 99.60 & -0.12 & 46.80 & -1.20 & 89.20 & -0.62 & 97.00 & -0.25 \\
\hline \multirow[t]{5}{*}{2014021} & WBC $\left(\times 10^{9} / L\right)$ & 7.90 & 8.14 & 0.48 & 7.64 & -0.51 & 7.58 & -0.62 & 7.90 & 0.01 \\
\hline & $\mathrm{RBC}\left(\times 10^{6} / \mu \mathrm{L}\right)$ & 4.53 & 4.56 & 0.13 & 4.53 & -0.01 & 4.45 & -0.36 & 4.51 & -0.09 \\
\hline & $\mathrm{Hb}(\mathrm{g} / \mathrm{L})$ & 130.3 & 131 & 0.26 & 131 & 0.26 & 130 & -0.13 & 130 & -0.13 \\
\hline & Hct (proportion of 1.0) & 0.40 & 0.42 & 1.11 & 0.42 & 0.87 & 0.41 & 0.44 & 0.37 & -1.67 \\
\hline & $\mathrm{PLT}\left(\times 10^{9} / \mathrm{L}\right)$ & 235.30 & 238.00 & 0.14 & 228.00 & -0.37 & 217.00 & -0.93 & 235.00 & -0.02 \\
\hline \multirow[t]{5}{*}{2014031} & WBC $\left(\times 10^{9} / L\right)$ & 3.22 & 3.27 & 0.19 & 3.19 & -0.13 & 3.20 & -0.09 & 3.36 & 0.55 \\
\hline & $\mathrm{RBC}\left(\times 10^{6} / \mu \mathrm{L}\right)$ & 2.19 & 2.11 & -0.39 & 2.25 & 0.33 & 2.19 & 0.02 & 2.17 & -0.08 \\
\hline & $\mathrm{Hb}(\mathrm{g} / \mathrm{L})$ & 55.1 & 54 & -0.63 & 56 & 0.47 & 55 & -0.08 & 57 & 1.02 \\
\hline & Hct (proportion of 1.0) & 0.17 & 0.17 & -0.01 & 0.18 & 1.12 & 0.17 & 0.67 & 0.15 & -2.02 \\
\hline & $\mathrm{PLT}\left(\times 10^{9} / \mathrm{L}\right)$ & 71.30 & 65.00 & -0.77 & 70.00 & -0.16 & 67.00 & -0.53 & 70.00 & -0.16 \\
\hline \multirow[t]{2}{*}{2014036} & PT INR & 1.05 & 1.03 & -0.24 & 1.00 & -0.70 & 1.05 & 0.06 & 1.05 & 0.06 \\
\hline & aPTा (s) & 29.18 & 31.80 & 0.85 & 25.50 & -1.19 & 34.50 & 1.72 & 34.00 & 1.56 \\
\hline
\end{tabular}


Sung JY, et al.

Pediatric reference intervals in Korean population

Supplemental Data Table S4. Continued

\begin{tabular}{|c|c|c|c|c|c|c|c|c|c|c|}
\hline \multirow{2}{*}{ Sample } & \multirow{2}{*}{ Test } & \multirow{2}{*}{ Mean* } & \multicolumn{2}{|c|}{ SNUH } & \multicolumn{2}{|c|}{ AMC } & \multicolumn{2}{|c|}{ SNUBH } & \multicolumn{2}{|c|}{ KSHH } \\
\hline & & & Value & SDI* & Value & SDI & Value & SDI & Value & SDI \\
\hline \multirow[t]{5}{*}{2014041} & WBC $\left(\times 10^{9} / L\right)$ & 23.58 & & & 22.56 & -0.81 & 22.35 & -0.97 & 24.55 & 0.77 \\
\hline & $\mathrm{RBC}\left(\times 10^{6} / \mu \mathrm{L}\right)$ & 5.18 & & & 5.11 & -0.12 & 5.09 & -0.16 & 5.15 & -0.05 \\
\hline & $\mathrm{Hb}(\mathrm{g} / \mathrm{L})$ & 160.0 & & & 158 & -0.55 & 160 & -0.00 & 164 & 1.08 \\
\hline & Hct (proportion of 1.0) & 0.49 & & & 0.50 & 0.47 & 0.50 & 0.39 & 0.43 & -2.08 \\
\hline & $\mathrm{PLT}\left(\times 10^{9} / \mathrm{L}\right)$ & 447.75 & & & 454.00 & -0.81 & 433.00 & -0.27 & 442.00 & -0.11 \\
\hline \multirow[t]{5}{*}{2015011} & $\mathrm{WBC}\left(\times 10^{9} / \mathrm{L}\right)$ & 8.67 & & & 7.86 & -0.04 & & & 8.39 & -0.01 \\
\hline & $\mathrm{RBC}\left(\times 10^{6} / \mu \mathrm{L}\right)$ & 4.58 & & & 4.49 & -0.09 & & & 4.47 & -0.11 \\
\hline & $\mathrm{Hb}(\mathrm{g} / \mathrm{L})$ & 132.6 & & & 131 & -0.63 & & & 132 & -0.24 \\
\hline & Hct (proportion of 1.0) & 0.41 & & & 0.42 & 0.55 & & & 0.37 & -1.96 \\
\hline & $\mathrm{PLT}\left(\times 10^{9} / \mathrm{L}\right)$ & 229.68 & & & 222.00 & -0.44 & & & 215.00 & -0.83 \\
\hline \multirow[t]{2}{*}{2015016} & PT INR & 3.32 & & & 3.32 & 0.07 & & & 2.97 & -0.47 \\
\hline & $\mathrm{aPT}(\mathrm{s})$ & 66.37 & & & 47.90 & -1.77 & & & 65.00 & -0.13 \\
\hline \multirow[t]{5}{*}{2015021} & $\mathrm{WBC}\left(\times 10^{9} / \mathrm{L}\right)$ & 23.02 & & & 22.57 & -0.07 & & & 23.50 & 0.08 \\
\hline & $\mathrm{RBC}\left(\times 10^{6} / \mu \mathrm{L}\right)$ & 5.08 & & & 4.96 & -0.64 & & & 5.00 & -0.43 \\
\hline & $\mathrm{Hb}(\mathrm{g} / \mathrm{L})$ & 158.2 & & & 157 & -0.38 & & & 60 & 0.59 \\
\hline & Hct (proportion of 1.0) & 0.48 & & & 0.48 & 0.19 & & & 0.42 & -2.03 \\
\hline & $\mathrm{PLT}\left(\times 10^{9} / \mathrm{L}\right)$ & 457.64 & & & 411.00 & -1.29 & & & 442.00 & -0.43 \\
\hline \multirow[t]{5}{*}{2015031} & $\mathrm{WBC}\left(\times 10^{9} / \mathrm{L}\right)$ & 8.34 & & & & & & & 8.38 & 0.11 \\
\hline & $\mathrm{RBC}\left(\times 10^{6} / \mu \mathrm{L}\right)$ & 4.64 & & & & & & & 4.58 & -0.27 \\
\hline & $\mathrm{Hb}(\mathrm{g} / \mathrm{L})$ & 130.6 & & & & & & & 129 & -0.65 \\
\hline & Hct (proportion of 1.0) & 0.39 & & & & & & & 0.36 & -1.57 \\
\hline & $\mathrm{PLT}\left(\times 10^{9} / \mathrm{L}\right)$ & 234.19 & & & & & & & 237.00 & 0.13 \\
\hline \multirow[t]{2}{*}{2015035} & PT INR & 1.05 & & & & & & & 1.05 & 0.04 \\
\hline & aPTा (s) & 28.98 & & & & & & & 32.20 & 0.83 \\
\hline
\end{tabular}

*Mean value and SDI were calculated based on the results of all instruments.

Abbreviations: SNUH, Seoul National University Hospital; AMC, Asan Medical Center; SNUBH, Seoul National University Bundang Hospital; KSHH, Kangnam Sacred Heart Hospital; RBC, red blood cells; WBC, white blood cells; PT, prothrombin time; INR, international normalized ratio; PLTs, platelets; SDI, standard deviation index. 
Supplemental Data Table S5. Median value for hematology and coagulation tests and estimated $P$ when the results of hematology and coagulation tests from other institutes were compared to those from SNUH, using the Mann-Whitney $U$ test

\begin{tabular}{|c|c|c|c|c|c|c|c|c|c|}
\hline \multirow{2}{*}{ Test } & \multirow{2}{*}{ Age } & \multirow{2}{*}{ Sex } & SNUH & AMC & \multirow{2}{*}{$P$} & SNUBH & \multirow{2}{*}{$P$} & KSHH & \multirow{2}{*}{$P$} \\
\hline & & & Median & Median & & Median & & Median & \\
\hline \multirow[t]{5}{*}{$\mathrm{WBC}\left(\times 10^{9} / \mathrm{L}\right)$} & $0-3 \mathrm{mo}$ & M & 11.67 & $\mathrm{~N} / \mathrm{A}$ & $\mathrm{N} / \mathrm{A}$ & 12.12 & 0.669 & $N / A$ & $\mathrm{~N} / \mathrm{A}$ \\
\hline & & $\mathrm{F}$ & 11.08 & 8.40 & 0.081 & N/A & $\mathrm{N} / \mathrm{A}$ & $N / A$ & $\mathrm{~N} / \mathrm{A}$ \\
\hline & 4-11 mo & Both & 9.39 & 10.60 & 0.004 & 10.35 & 0.159 & 8.63 & 0.979 \\
\hline & $1-6 \mathrm{yr}$ & Both & 8.33 & 8.90 & 0.031 & 8.37 & 0.725 & 8.34 & 0.670 \\
\hline & $7-18 \mathrm{yr}$ & Both & 6.68 & 8.30 & $<0.001$ & 6.91 & 0.408 & 6.42 & 0.343 \\
\hline \multirow[t]{2}{*}{$\operatorname{ANC}\left(\times 10^{9} / L\right)$} & 0-11 mo & Both & 1.68 & 1.98 & 0.137 & 2.03 & 0.799 & $N / A$ & $N / A$ \\
\hline & $1-18 \mathrm{yr}$ & Both & 3.12 & 3.28 & $<0.001$ & 3.37 & 0.094 & $N / A$ & $\mathrm{~N} / \mathrm{A}$ \\
\hline \multirow{4}{*}{$\begin{array}{l}\text { Segmented neutrophils } \\
(\%)\end{array}$} & 0-11 mo & Both & 17.4 & 19.1 & 0.689 & 20.1 & 0.349 & 25.2 & 0.051 \\
\hline & $1-6 \mathrm{yr}$ & Both & 34.3 & 31.0 & 0.037 & 41.3 & 0.002 & 37.9 & 0.023 \\
\hline & $7-12 \mathrm{yr}$ & Both & 47.5 & 53.8 & 0.163 & 45.9 & 0.693 & 52.2 & 0.196 \\
\hline & $13-18 \mathrm{yr}$ & Both & 53.0 & 80.6 & $<0.001$ & 54.4 & 0.169 & 53.3 & 0.830 \\
\hline \multirow[t]{4}{*}{ Lymphocytes (\%) } & 0-11 mo & Both & 71.2 & 71.4 & 0.306 & 70.6 & 0.458 & 61.7 & 0.029 \\
\hline & $1-6 \mathrm{yr}$ & Both & 54.3 & 59.3 & 0.039 & 48.1 & 0.004 & 47.2 & 0.001 \\
\hline & $7-12 \mathrm{yr}$ & Both & 43.1 & 38.2 & 0.206 & 43.5 & 0.673 & 37.9 & 0.052 \\
\hline & $13-18 \mathrm{yr}$ & Both & 36.6 & 13.5 & $<0.001$ & 34.8 & 0.164 & 37.0 & 0.933 \\
\hline Monocytes (\%) & All & Both & 6.2 & 5.7 & 0.001 & 5.6 & $<0.001$ & 4.5 & $<0.001$ \\
\hline \multirow[t]{2}{*}{ Eosinophils (\%) } & All & M & 3.1 & 2.4 & 0.009 & 2.8 & 0.753 & 3.1 & 0.785 \\
\hline & & $\mathrm{F}$ & 2.3 & 2.4 & 0.509 & 2.2 & 0.779 & 2.6 & 0.190 \\
\hline Basophils (\%) & All & Both & 0.3 & 0.3 & 0.293 & 0.4 & 0.104 & 0.6 & $<0.001$ \\
\hline \multirow[t]{3}{*}{$\mathrm{RBC}\left(\times 10^{6} / \mu \mathrm{L}\right)$} & $0-3 \mathrm{mo}$ & Both & 3.88 & 3.44 & 0.027 & 3.75 & 0.576 & $\mathrm{~N} / \mathrm{A}$ & $\mathrm{N} / \mathrm{A}$ \\
\hline & $4 \mathrm{mo}-18 \mathrm{yr}$ & M & 4.82 & 4.68 & 0.010 & 4.68 & 0.111 & 4.81 & 0.416 \\
\hline & & $F$ & 4.54 & 4.48 & 0.101 & 4.55 & 0.968 & 4.60 & 0.180 \\
\hline \multirow[t]{11}{*}{ MCV (fL) } & $0-3 \mathrm{mo}$ & Both & 87.0 & 98.9 & 0.001 & 83.2 & 0.704 & $\mathrm{~N} / \mathrm{A}$ & $\mathrm{N} / \mathrm{A}$ \\
\hline & 4-11 mo & M & 75.8 & 76.3 & 0.391 & 72.3 & 0.097 & 72.4 & 0.381 \\
\hline & & $F$ & 78.0 & 78.5 & 0.171 & 79.5 & 0.106 & 70.9 & 0.319 \\
\hline & $1-6 \mathrm{yr}$ & M & 77.9 & 78.0 & 0.499 & 79.2 & 0.064 & 78.4 & 0.509 \\
\hline & & $\mathrm{F}$ & 80.1 & 79.4 & 0.811 & 80.1 & 0.567 & 79.9 & 0.833 \\
\hline & $7-12 \mathrm{yr}$ & M & 81.2 & 82.7 & 0.363 & 82.9 & 0.169 & 80.3 & 0.663 \\
\hline & & $\mathrm{F}$ & 83.9 & 85.4 & 0.268 & 82.6 & 0.074 & 84.5 & 0.505 \\
\hline & $13-15 \mathrm{yr}$ & M & 84.6 & 82.2 & 0.418 & 84.3 & 0.880 & 85.2 & 0.588 \\
\hline & & $\mathrm{F}$ & 87.5 & 87.5 & 0.787 & 90.9 & 0.230 & 84.5 & 0.028 \\
\hline & $13-18 \mathrm{yr}$ & M & 87.6 & 88.3 & 0.745 & 86.0 & 0.342 & 85.0 & 0.066 \\
\hline & & $\mathrm{F}$ & 90.0 & 88.4 & 0.085 & 89.8 & 0.938 & 84.6 & 0.006 \\
\hline \multirow[t]{7}{*}{ MCH (pg) } & $0-3$ mo & Both & 29.6 & 33.9 & 0.002 & 29.2 & 0.947 & $\mathrm{~N} / \mathrm{A}$ & $\mathrm{N} / \mathrm{A}$ \\
\hline & 4-11 mo & M & 25.9 & 25.9 & 0.508 & 24.8 & 0.250 & 25.4 & 0.806 \\
\hline & & $\mathrm{F}$ & 26.5 & 26.8 & 0.248 & 27.9 & 0.021 & 23.6 & 0.405 \\
\hline & $1-6 \mathrm{yr}$ & Both & 27.1 & 27.0 & 0.390 & 27.6 & 0.010 & 27.4 & 0.329 \\
\hline & $7-12 \mathrm{yr}$ & Both & 28.2 & 28.7 & 0.406 & 28.5 & 0.637 & 28.8 & 0.550 \\
\hline & $13-15 y r$ & Both & 29.4 & 28.7 & 0.935 & 29.9 & 0.087 & 29.8 & 0.737 \\
\hline & $16-18 \mathrm{yr}$ & Both & 30.3 & 30.2 & 0.678 & 31.0 & 0.098 & 29.3 & 0.018 \\
\hline \multirow[t]{3}{*}{ MCHC (g/L) } & $0-12 \mathrm{yr}$ & Both & 340 & 341 & 0.013 & 342 & 0.005 & 344 & 0.042 \\
\hline & $13-18 \mathrm{yr}$ & M & 344 & 342 & 0.376 & 345 & 0.007 & 344 & 0.312 \\
\hline & & $\mathrm{F}$ & 339 & 341 & 0.003 & 345 & 0.003 & 346 & 0.080 \\
\hline
\end{tabular}


Sung JY, et al.

Pediatric reference intervals in Korean population

Supplemental Data Table S5. Continued

\begin{tabular}{|c|c|c|c|c|c|c|c|c|c|}
\hline \multirow{2}{*}{ Test } & \multirow{2}{*}{ Age } & \multirow{2}{*}{ Sex } & SNUH & AMC & \multirow{2}{*}{$P$} & SNUBH & \multirow{2}{*}{$P$} & KSHH & \multirow{2}{*}{$P$} \\
\hline & & & Median & Median & & Median & & Median & \\
\hline \multirow[t]{6}{*}{$\mathrm{Hb}(\mathrm{g} / \mathrm{L})$} & 0-3 mo & Both & 114 & 111 & 0.551 & 111 & 0.704 & $\mathrm{~N} / \mathrm{A}$ & $\mathrm{N} / \mathrm{A}$ \\
\hline & $7-12 \mathrm{yr}$ & $M$ & 137 & 134 & 0.483 & 131 & 0.253 & 138 & 0.561 \\
\hline & & $\mathrm{F}$ & 132 & 132 & 0.846 & 132 & 0.714 & 132 & 0.376 \\
\hline & & $\mathrm{F}$ & 133 & 137 & 0.986 & 132 & 0.647 & 134 & 0.843 \\
\hline & $16-18 \mathrm{yr}$ & $M$ & 152 & 158 & 0.914 & 157 & 0.594 & 154 & 0.594 \\
\hline & & $\mathrm{F}$ & 132 & 122 & 0.009 & 136 & 0.260 & 137 & 0.667 \\
\hline \multirow[t]{4}{*}{ Hct (proportion of 1.0) } & $0-3 \mathrm{mo}$ & Both & 0.34 & 0.32 & 0.380 & 0.32 & 0.407 & N/A & N/A \\
\hline & $4 \mathrm{mo}-6 \mathrm{yr}$ & Both & 0.37 & 0.36 & $<0.001$ & 0.37 & 0.829 & 0.38 & 0.023 \\
\hline & $16-18 \mathrm{yr}$ & $M$ & 0.45 & 0.45 & 0.691 & 0.45 & 0.652 & 0.45 & 0.653 \\
\hline & & $\mathrm{F}$ & 0.39 & 0.36 & 0.001 & 0.40 & 0.735 & 0.41 & 0.845 \\
\hline \multirow[t]{4}{*}{ RDW (\%) } & 0-3 mo & Both & 14.0 & 15.4 & 0.024 & 14.0 & 0.947 & N/A & N/A \\
\hline & $4 \mathrm{mo}-6 \mathrm{yr}$ & $M$ & 13.1 & 13.1 & 0.841 & 13.0 & 0.349 & 12.9 & 0.041 \\
\hline & & $\mathrm{F}$ & 12.8 & 12.9 & 0.467 & 12.8 & 0.557 & 12.7 & 0.513 \\
\hline & $7-y r$ & Both & 12.7 & 12.6 & 0.385 & 12.6 & 0.333 & 12.5 & 0.195 \\
\hline ESR (mm/hr) & All & Both & 3 & 2 & 0.002 & 5 & $<0.001$ & 4 & 0.625 \\
\hline \multirow[t]{2}{*}{ Platelets $\left(\times 10^{9} / \mathrm{L}\right)$} & 0-3 mo & Both & 409 & 421 & 0.358 & 449 & 0.517 & $\mathrm{~N} / \mathrm{A}$ & $\mathrm{N} / \mathrm{A}$ \\
\hline & 4-11 mo & Both & 347 & 385 & 0.003 & 414 & 0.202 & 480 & 0.082 \\
\hline PDW (\%) & All & Both & 10.6 & 9.7 & $<0.001$ & 10.2 & 0.004 & 46.8 & $<0.001$ \\
\hline \multirow[t]{2}{*}{ PT INR } & 0-11 mo & Both & 1.00 & 0.96 & $<0.001$ & 1.00 & 0.845 & 1.09 & 0.001 \\
\hline & $1-18 \mathrm{yr}$ & Both & 1.06 & 0.99 & $<0.001$ & 1.03 & 0.001 & 1.11 & $<0.001$ \\
\hline \multirow[t]{2}{*}{ PT (\%) } & 0-11 mo & Both & 100.0 & 109.2 & $<0.001$ & 100.0 & 0.836 & 89.0 & 0.002 \\
\hline & $1-18 \mathrm{yr}$ & Both & 92.0 & 103.7 & $<0.001$ & 95.0 & 0.075 & 88.0 & $<0.001$ \\
\hline \multirow[t]{2}{*}{ PT (s) } & 0-11 mo & Both & 11.0 & 10.8 & 0.192 & 12.9 & $<0.001$ & 11.7 & 0.004 \\
\hline & $1-18 \mathrm{yr}$ & Both & 11.5 & 11.1 & $<0.001$ & 13.2 & $<0.001$ & 11.9 & $<0.001$ \\
\hline aPTT (s) & All & Both & 34.5 & 28.9 & $<0.001$ & 40.1 & $<0.001$ & 36.1 & 0.001 \\
\hline \multirow[t]{2}{*}{ Fibrinogen (g/dL) } & $0-12 \mathrm{yr}$ & Both & 239 & $\mathrm{~N} / \mathrm{A}$ & $\mathrm{N} / \mathrm{A}$ & $\mathrm{N} / \mathrm{A}$ & $\mathrm{N} / \mathrm{A}$ & $\mathrm{N} / \mathrm{A}$ & $\mathrm{N} / \mathrm{A}$ \\
\hline & $13-18 \mathrm{yr}$ & Both & 272 & N/A & N/A & $N / A$ & N/A & $\mathrm{N} / \mathrm{A}$ & $\mathrm{N} / \mathrm{A}$ \\
\hline
\end{tabular}

$P<0.05$ indicates a significant difference.

Abbreviations: SNUH, Seoul National University Hospital; AMC, Asan Medical Center; SNUBH, Seoul National University Bundang Hospital; KSHH, Kangnam Sacred Heart Hospital; N/A, not available; WBC, white blood cells; ANC, absolute neutrophil count; RBC, red blood cells; MCV, mean corpuscular volume; $\mathrm{MCH}$, mean corpuscular hemoglobin; MCHC, mean corpuscular hemoglobin concentration; RDW, RBC distribution width; ESR, erythrocyte sedimentation rate; PDW, platelet distribution width; PT, prothrombin time; INR, international normalized ratio; yr, year; mo, month. 
A

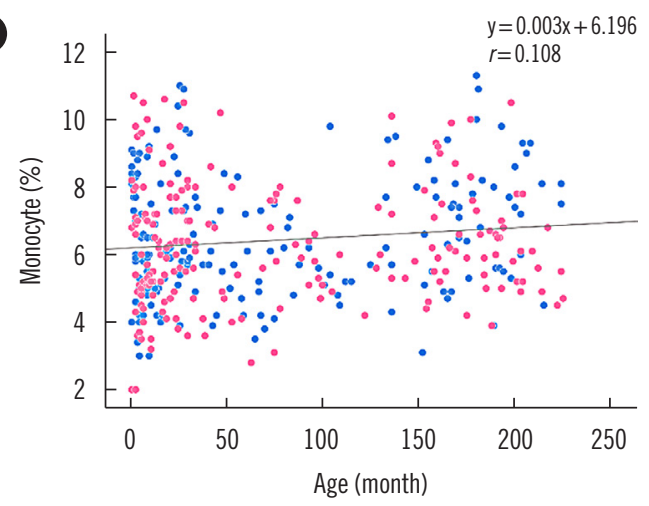

C

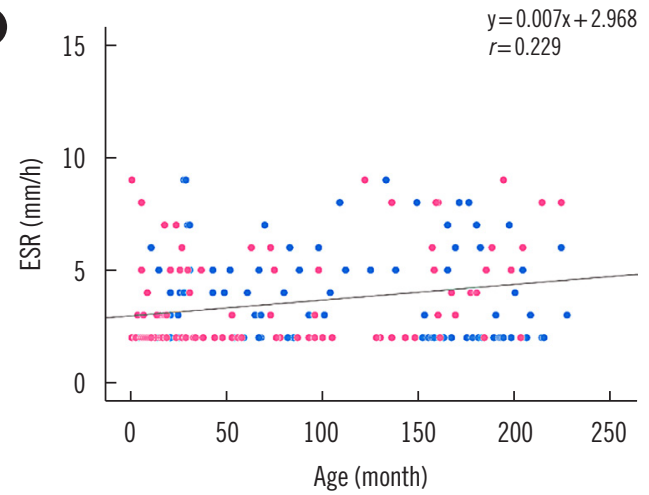

E

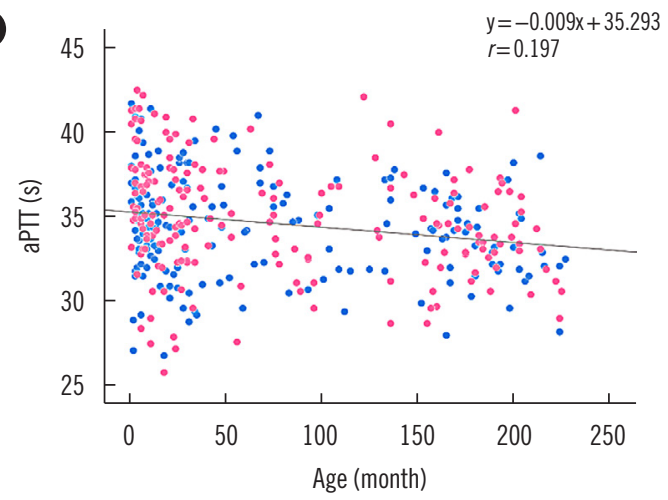

B

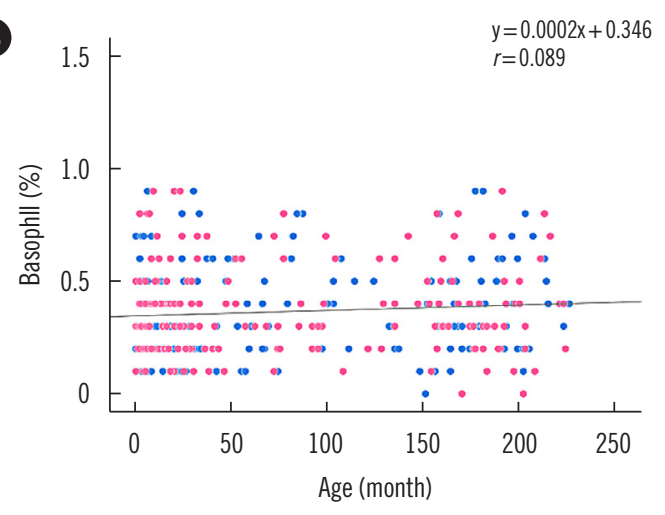

D

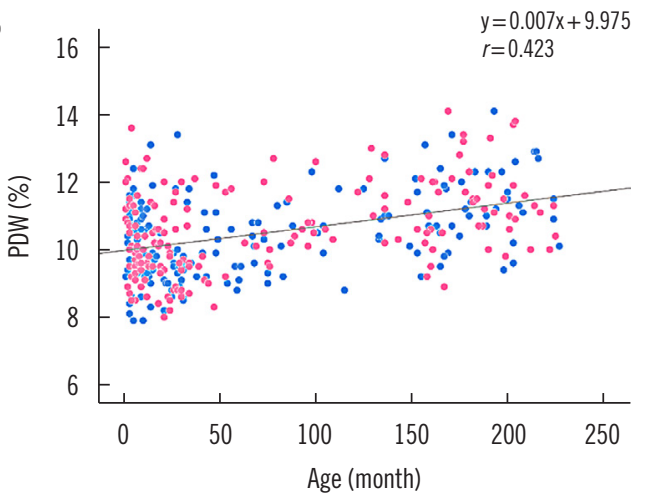

Supplemental Data Figure S1. Scatter plots of hematology and coagulation test results that did not show age-dependent changes. Results obtained at SNUH using the Sysmex XE-2100 platform for hematology and the ACL TOP platform for coagulation testing are presented. (AD) Percentages of monocytes, basophils, ESR, and PDW. (E) aPTT. Blue and red dots represent male and female children enrolled in the present study.

Abbreviations: SNUH, Seoul National University Hospital; RDW, RBC distribution width; PCT, plateletcrit; aPTT, activated partial thromboplastin time. 
Sung JY, et al.

Pediatric reference intervals in Korean population

A

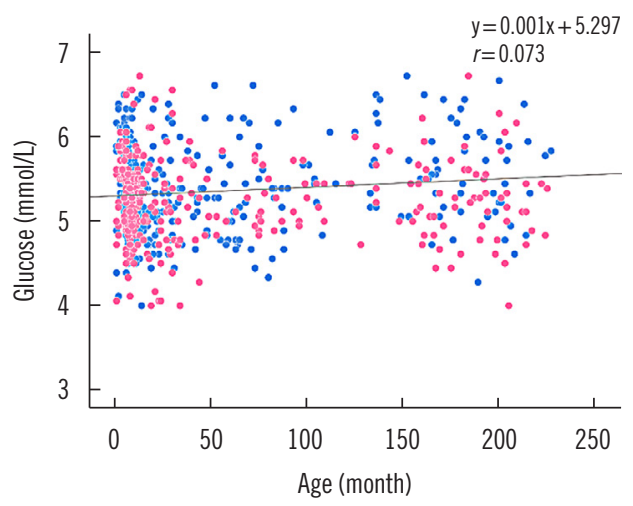

C

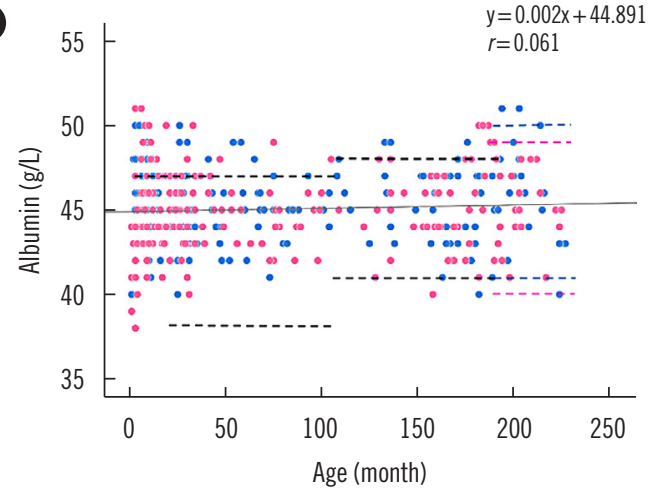

E

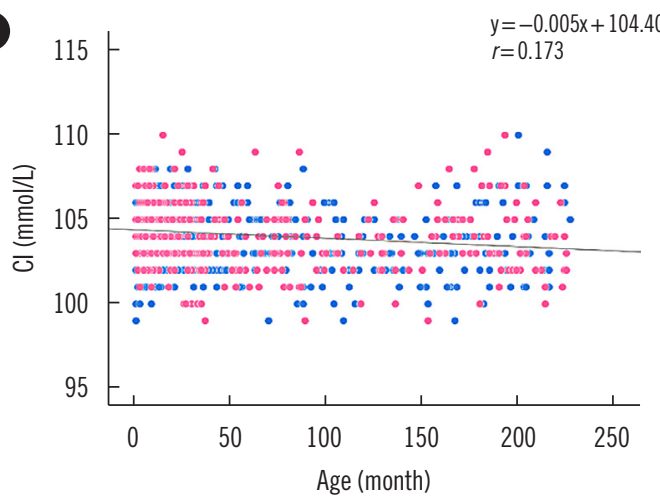

B

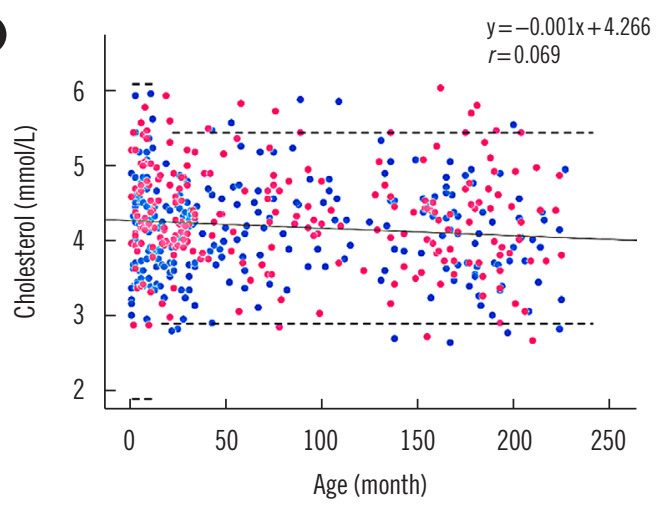

D

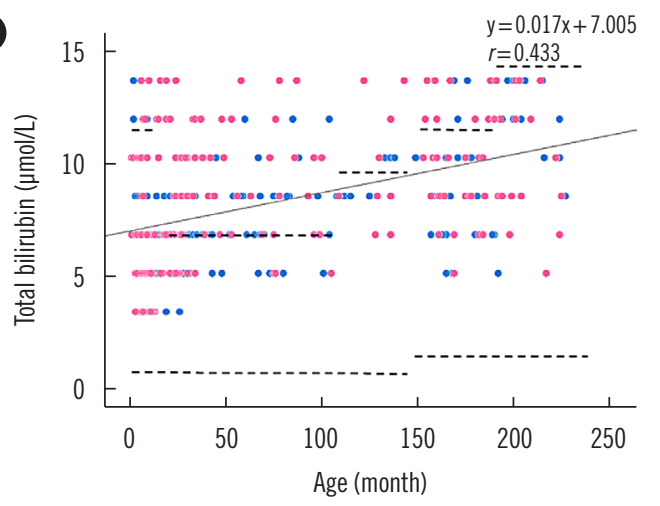

F

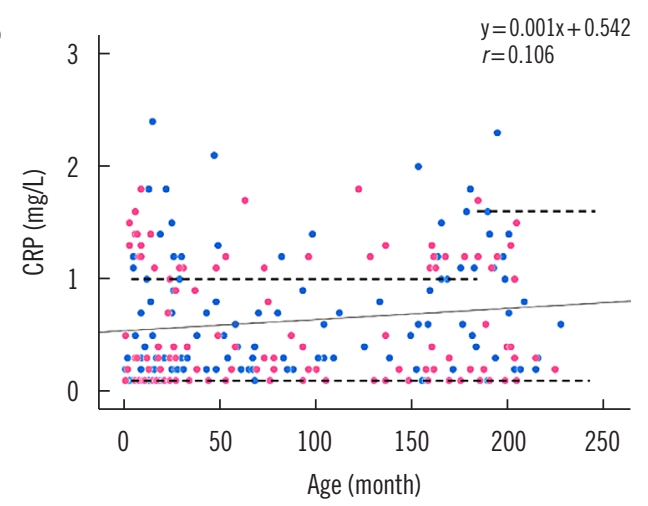

Supplemental Data Figure S2. Scatter plots of clinical chemistry test results that did not show age-dependent changes, and the difference between results obtained in this study and reference intervals established previously based mainly on a Caucasian population. All test results that passed method comparison, considered mergeable, and used in multicenter analysis are plotted. (A-F) Glucose, cholesterol, albumin, total bilirubin, $\mathrm{Cl}$, and CRP. Blue and red dots represent male and female children enrolled in the present study. Blue, red, and black dashed lines represent male, female, and common reference limits established in a previous study, respectively.

Abbreviations: $\mathrm{Cl}$, Chloride, $\mathrm{CRP}$, C-reactive protein. 